Research Article

\title{
Development of the Fog Seal Layer Characterized by Durability in Terms of Skid Resistance
}

\author{
Yingjun Jiang $(\mathbb{D}$, Jiangtao Fan $(\mathbb{D}$, Pengyu Lv $\mathbb{D}$, Kejia Yuan $(\mathbb{D}$, Yong Yi $\mathbb{D}$, \\ Tian Tian $(D$, and Chenfan Bai
} Key Laboratory for Special Area Highway Engineering of Ministry of Education, Chang'an University, Xi'an 710064,
Shanxi, China

Correspondence should be addressed to Jiangtao Fan; 2020021070@chd.edu.cn

Received 31 July 2021; Accepted 13 October 2021; Published 5 November 2021

Academic Editor: Shengwen Tang

Copyright (C) 2021 Yingjun Jiang et al. This is an open access article distributed under the Creative Commons Attribution License, which permits unrestricted use, distribution, and reproduction in any medium, provided the original work is properly cited.

In this paper, based on the thermosetting properties, bonding performance, high-temperature water damage resistance, and aging resistance properties of epoxy-emulsified asphalt, the best formulation of epoxy emulsified asphalt as a skid resistance fog sealing asphalt is studied. Through accelerated wheel wear and other tests, the effects of the ratio of the amount of skid resistance particles to the amount of epoxy emulsified asphalt, the total amount of skid resistance fog seal asphalt, and the construction process on the skid resistance durability of the skid resistance fog seal were studied. The results show that the epoxy emulsified asphalt formula code $A_{80}\left(E_{2}\right)$ (emulsified asphalt: water-based epoxy=80:20) is the best formula; when the proportion of emery and epoxy emulsified asphalt is $1: 1$, the British Pendulum Number (BPN) reduction rate of the skid resistance fog seal-test piece worn 100,000 times was $27.4 \%$. Compared with the same period, the reduction rate was reduced by $4.6 \%$ on average, with the smallest mass loss rate and the best skid resistance durability. When the total amount of skid resistance fog seal asphalt is $1.2 \mathrm{~kg} / \mathrm{m}^{2}$, the BPN reduction rate of the skid resistance fog seal specimen worn 100,000 times was $27.4 \%$, which is an average reduction of $5.8 \%$ over the same period, and the mass loss rate is the smallest, and the skid resistance durability optimal. When using the premixed process, the BPN of the specimen was reduced by $13.2 \%$ after abrasion of 100,000 times. Compared with the "one asphalt and one sand" and "double asphalt and one sand" molded specimens, the mass loss rate was reduced by $15.0 \%, 4 \mathrm{eU} \& 7.2 \%$, showing the best skid resistance performance. The results can provide guidance for the design and construction of AC-13 and other pavement skid resistance fog seals.

\section{Introduction}

Skid resistance fog seal layers (also known as sand fog seal layers) are composed of diluted liquid asphalt (emulsified asphalt or modified emulsified asphalt), fine aggregate, and catalyst. The layers can penetrate the gaps of aggregates and flow into pores, thereby restoring the adhesion of asphalt on the road surface, filling tiny cracks and voids, and preventing the road surface from underwater seeping [1]. Simultaneously, the sprayed fine aggregate provides good skid capability, strengthens the bonding of loose stones and pavement materials, delays the aging of the asphalt film of the road surface, prevents various types of damage caused by the asphalt film peeling, and beautifies the road surface $[2,3]$.
These layers can effectively reduce the lifecycle cost of pavements and present a cost-effective preventive maintenance technology [4-7].

Scholars globally have studied the two composition materials (skid resistance particles and fog sealing asphalt) and their influence on the performance of the skid resistance fog seal layer.

In research on fog sealing asphalt, studies by Im, Jeong Hyuk [8] have shown that polymer-modified emulsifiers exhibit better cohesive and impermeable properties than unmodified emulsifiers. Research by $\mathrm{Hu}$ et al. [9] showed that the water-based epoxy resin in the water-based epoxy asphalt modified emulsion (WEB) can significantly improve the skid resistance and durability of the fog-sealed pavement. Feng et al. 
[10] evaluated the skid resistance performance of the Tianjin BEST microsealing bonding reductant, the American Master seal, and a new type of bio-oil modified fog seal with sand based on an aggregate image. Measurement System II is a new method for evaluating the surface characteristics of solid fog seals with sand materials. Fei et al. [11] studied the uniform stability, setting time, and bonding strength of three sand fog seal materials mixed with water-based epoxy resin and analyzed the effects of different water-based epoxy resin content for sand fog seal material properties. To overcome the durability shortcomings of reduced skid resistance and insufficient wear resistance of hydrophobic emulsified asphalt coatings, Han et al. [12] proved that $12 \%$ WEB content is the best by conducting accelerated wear tests. Jiu-peng et al. [13] showed that considering the permeability and skid resistance performance of the pavement comprehensively, the spraying amount of the fog seal layer should be between 0.2 and $0.4 \mathrm{~kg} / \mathrm{m}^{2}$.

In a study on skid resistance particles, Estakhri and Agarwal [14] showed that spraying fine sand in the fog seal layer could prevent the rapid decline in the pavement's skid resistance performance in the short term. Richard et al. [15] found that the spraying of fine sand on the fog seal can prevent the rapid decline in the skid resistance performance of the road surface in the short term. After the fog seal is constructed for 45-60 minutes, the skid resistance performance of the road can be restored to the original road surface within 24 hours. To optimize the application rate of the mist seal layer and regenerant seal, Qureshi et al. [16] studied and evaluated the friction performance and durability of three different types of mist seal layer. Aiming at the problem that the fog seal affects the skid resistance performance of the pavement, Chen et al. [17] used the tire-driven pavement function accelerated loading test system to simulate the actual pavement friction and studied the skid resistance performance of the fog seal spread with skid resistance particles.

For the construction technology of the skid resistance fog seal layer, research by $\mathrm{Li}$ et al. [18] showed that simultaneous spraying of $0.3 \mathrm{~kg} / \mathrm{m}^{2}-0.35 \mathrm{~kg} / \mathrm{m}^{2}$ solvent-based emulsified asphalt and $0.25 \mathrm{~kg} / \mathrm{m}^{2}$ emery can improve the skid resistance performance. Yuan and Center [19] have shown that compared with traditional antifog sealant coatings, antislip antifog sealant coatings can improve the antislip performance of pavement and improve the antislip performance of pavement. Then, according to the highway application case, the raw material requirements of the antiskid mist seal layer and the quality control standards of the construction process are summarized.

The above research shows that scholars globally have conducted much research on the material formulation and skid resistance performance of the skid resistance fog seal. However, after constructing the skid resistance fog seal, its skid resistance performance and bonding performance will rapidly decline because of vehicle load, tire friction, and other reasons [20]. Regardless of the road type, emulsifier, and usage, within three months, the international friction index parameter F-60 of the fog-sealed pavement will drop by $20 \%-40 \%$ and the surface of the fog seal will not return to the original friction level $[21,22]$. The lack of durability was neglected in the early days [23]. The amount and ratio of the fog sealing asphalt and skid resistance in the skid resistance fog seal layer are critical for its skid resistance durability. If the amount of fog sealing asphalt is too high, the skid resistance performance of the pavement will be significantly reduced. If the amount of fog sealing asphalt is too low, the bonding and waterproof effect cannot be achieved, and the imbalance of the ratio between fog sealing asphalt and skid resistance particles will significantly reduce the durability of the antiskid mist seal layer [24]. For construction technology, research from scholars globally is even rarer, and most of them are based on the construction technology of developed countries [25]. Therefore, this article conducts an indepth study of the above issues.

In view of this, this article has carried out research on the following aspects. First, the performance of the mist sealant binder was tested and the optimal fog sealing asphalt formulation was developed. Then the ratio of the amount of fog sealing asphalt and the amount of antiskid particles, the total amount of skid resistance fog sealing asphalt, and the influence of different construction techniques on the BPN of the fog sealing asphalt test piece and the mass loss rate after abrasion were studied, and the amount of skid resistance particles the best ratio with the amount of fog sealing asphalt, the best total amount of skid resistance fog sealing asphalt, and the best construction technology were determined. Finally, the superiority of the recommended skid resistance fog sealing asphalt is verified by the microscopic analysis of the epoxy emulsified asphalt solidification and the BPN abrasion law and the mass loss rate of different asphalt skid resistance fog sealing asphalt samples.

\section{Materials and Experiment Method}

\subsection{Raw Material}

2.1.1. Fog Sealing Asphalt. The research group independently developed the fog sealing asphalt. The principal components are BE-4-type emulsified asphalt, E-44-type water-based epoxy resin emulsion, and a water-based curing agent. Figure 1 shows the three components of epoxyemulsified asphalt.

(1) Waterborne Epoxy Resin Emulsion. Using the reverse method, the E-44-type epoxy resin is emulsified using emulsifier A with the best HLB value to prepare the waterbased epoxy resin emulsion [25]. According to the GB/T 38990-2020 [26], the E-44 epoxy resin was tested and its technical properties are shown in Table 1.

(2) Emulsified Asphalt. According to the compatibility test, the BE-4-type emulsified asphalt, which has the best compatibility with the water-based epoxy resin emulsion, is adopted. According to the specification [26-28], the BE-4 emulsified asphalt was tested, and its technical properties are shown in Table 2.

(3) Water-based Curing Agent. According to the compatibility test, the curing agent $A$ with the best compatibility with the BE-4-type emulsified asphalt was selected as the curing 


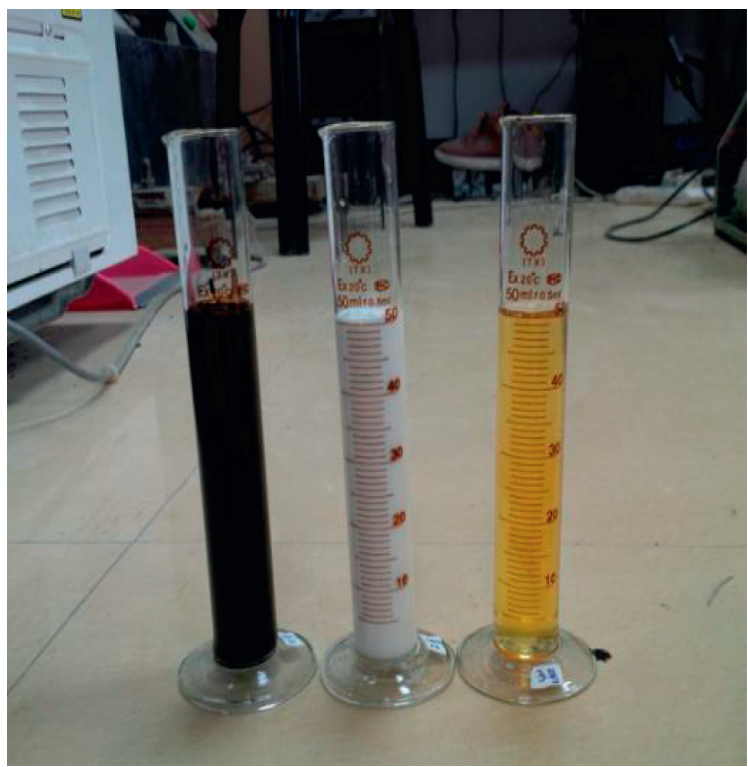

FIGURE 1: Three components of epoxy-emulsified asphalt. (left: emulsified asphalt for fog seal layer; middle: water-based epoxy resin emulsion; right: water-based curing agent).

TABLE 1: Technical properties of E-44 epoxy resin.

\begin{tabular}{|c|c|c|c|c|c|c|c|c|}
\hline Exterior & $\begin{array}{l}\text { Softening } \\
\text { point }\left({ }^{\circ} \mathrm{C}\right)\end{array}$ & $\begin{array}{c}\text { Epoxy } \\
\text { equivalent }\end{array}$ & $\begin{array}{c}\text { Shrinkage } \\
(\%)\end{array}$ & $\begin{array}{c}\text { Thermal } \\
\text { expansion } \\
\text { coefficient }(\%)\end{array}$ & $\begin{array}{c}\text { Epoxy value } \\
\text { (eq/100 g) }\end{array}$ & $\begin{array}{c}\text { Organic } \\
\text { chlorine (\%) }\end{array}$ & $\begin{array}{c}\text { Inorganic } \\
\text { chlorine } \\
(\mathrm{ppm})\end{array}$ & Volatile (\%) \\
\hline $\begin{array}{l}\text { Transparent } \\
\text { liquid }\end{array}$ & $16-24$ & $212.6 \sim 238.1$ & $<2$ & $6-10.2$ & $0.42-0.47$ & $\leq 0.5$ & $\leq 200$ & 1.0 \\
\hline
\end{tabular}

TABLE 2: Technical properties of BE-4 emulsified asphalt.

\begin{tabular}{|c|c|c|c|c|}
\hline \multicolumn{2}{|c|}{ Projects } & Measured value & Skills requirement & Experiment method \\
\hline \multicolumn{2}{|l|}{ Demulsification speed } & Slow crack & Slow crack & T0658 \\
\hline \multicolumn{2}{|c|}{ Particle charge } & + & Cation $(+)$ & T0653 \\
\hline \multicolumn{2}{|c|}{ Remaining amount on the sieve (1.18 $\mathrm{mm}$ sieve) (\%) } & 0.01 & $\ngtr 0.1$ & T0652 \\
\hline \multicolumn{2}{|c|}{ Engla viscometer E25 } & 3.5 & $1 \sim 6$ & T0622 \\
\hline \multirow{3}{*}{ Evaporation residue } & Content $(\%)$ & 50.7 & $\nless 50$ & T0651 \\
\hline & Penetration $\left(100 \mathrm{~g}, 25^{\circ} \mathrm{C}, 5 \mathrm{~s}\right)(0.1 \mathrm{~mm})$ & 88 & $50 \sim 300$ & T0604 \\
\hline & Ductility $\left(15^{\circ} \mathrm{C}\right)(\mathrm{cm})$ & $>100$ & $\nless 40$ & T0605 \\
\hline \multirow{2}{*}{$\begin{array}{l}\text { Storage stability at room temperature } \\
\text { Compatibility }(30 \mathrm{~min})\end{array}$} & $\begin{array}{l}1 \mathrm{~d}(\%) \\
5 \mathrm{~d}(\%)\end{array}$ & $\begin{array}{l}0.3 \\
2.8\end{array}$ & $\begin{array}{l}\ngtr 1 \\
\ngtr 5\end{array}$ & T0655 \\
\hline & & Qualified & Qualified & Blending method \\
\hline
\end{tabular}

agent used in the test. According to GB/T 38990-2020 [26], the curing agent $\mathrm{A}$ was tested, and its technical properties are shown in Table 3.

2.1.2. Skid Resistance Particles. According to research results [12], Table 4 shows the technical properties of the selected skid resistance particles, which can meet the requirements of the specification [26].

2.1.3. Asphalt Mixture. In the experiment, the AC-13 asphalt mixture was selected as the fog seal layer carrier, and the properties of the asphalt and aggregates used will not be mentioned. Table 5 shows the gradation of the asphalt mixture.

2.2. Test Plan. In all the following tests where replicates may be used, the number of specimens prepared shall be at least 4 .

2.2.1. Development of Fog Sealing Asphalt Formulation. Among the components of epoxy-emulsified asphalt, the emulsified asphalt is called the asphalt component and the blend system of the water-based epoxy resin emulsion and the water-based curing agent is called the epoxy system component. Take epoxy-emulsified asphalt $\left(\mathrm{A}_{80} \mathrm{E}_{2}\right)$ as an 
TABLe 3: Technical properties of the water-based curing agent.

\begin{tabular}{lccc}
\hline Active ingredient content $(\%)$ & Density $\left(\mathrm{g} / \mathrm{cm}^{3}\right)$ & Viscosity $(\mathrm{MPa} \cdot \mathrm{s})$ & Active hydrogen equivalent \\
\hline $50.0 \pm 1.0$ & $1.05-1.12$ & $5,000-20,000$ & 287 \\
\hline
\end{tabular}

TABle 4: The technical properties of the skid resistance particles.

\begin{tabular}{lccccc}
\hline \multirow{2}{*}{ Type of skid resistance particles } & \multirow{2}{*}{ Apparent density $\left(\mathrm{g} / \mathrm{cm}^{3}\right)$} & Water content $(\%)$ & \multicolumn{2}{c}{ Crushing value (\%) } & Gradation \\
& & & $0.6-1.18$ & $0.3-0.6$ & $0.6-1.18: 0.3-0.6$ \\
\hline Emery & 3.57 & 0.6 & 14.72 & 8.91 & $7: 3$ \\
\hline
\end{tabular}

TABle 5: Mineral grade grading of the AC-13 asphalt mixture.

\begin{tabular}{|c|c|c|c|c|c|c|c|c|c|c|}
\hline Screen size $(\mathrm{mm})$ & 16 & 13.2 & 9.5 & 4.75 & 2.36 & 1.18 & 0.6 & 0.3 & 0.15 & 0.075 \\
\hline Synthetic mass ratio $(\%)$ & 99.9 & 92.9 & 81.4 & 55.3 & 37.5 & 25.1 & 17.4 & 10.2 & 7.3 & 6.1 \\
\hline Percentage of required quality pass (\%) & 100 & $90-100$ & $68-85$ & $38-68$ & $24-50$ & $15-38$ & $10-28$ & $7-20$ & $5-15$ & $4-8$ \\
\hline
\end{tabular}

example, where A represents the asphalt component, E represents the epoxy system component, 80 is the asphalt component mass accounting for $80 \%$ of the total mass of the epoxy-emulsified asphalt, and 2 represents the remaining epoxy system components. The mass ratio of water-based epoxy resin emulsion to a water-based curing agent is $2: 1$.

Based on the previous research results [29] and comprehensively considering the thermosetting properties of the fog sealing asphalt, the formulation of the fog sealing asphalt is initially determined. Then, within the scope of the primary formulation, according to the influence of the components and proportions of various properties, an optimal formulation of the fog sealing asphalt is selected.

2.2.2. Research on Influencing Factors of Skid Resistance Durability of the Skid Resistance Fog Seal. For the research on the factors affecting the skid resistance durability of the fog seal layer, this article plans to conduct the following three aspects: first, study the influence of the ratio of the number of antiskid particles to the amount of mist seal asphalt on the antiskid durability of the mist seal layer. In the test, epoxyemulsified asphalt of $0.6 \mathrm{~kg} / \mathrm{m}^{2}$ was used as the basis; use emery and epoxy-emulsified asphalt with a mass ratio of $4: 6$, $5: 6,1: 1,7: 6$, and $8: 6$, select the best dosage based on the change in BPN and the rate of abrasion mass loss, and analyze its laws. Second, the effect of skid resistance fog sealing asphalt dosage on the performance of skid resistance fog seal is studied. The skid resistance fog sealing asphalt is divided into skid resistance particle components and fog sealing asphalt components. This test selects the total amount of skid resistance fog sealing asphalt at $0.8 \mathrm{~kg} / \mathrm{m}^{2}$, $1.0 \mathrm{~kg} / \mathrm{m}^{2}, 1.2 \mathrm{~kg} / \mathrm{m}^{2}, 1.4 \mathrm{~kg} / \mathrm{m}^{2}$, and $1.6 \mathrm{~kg} / \mathrm{m}^{2}$; the best choice is based on the change in BPN, and the rate of abrasion mass loss dosage and its law are analyzed. Finally, the influence of construction technology on the performance of the skid resistance fog seal is studied. It is planned to use the one asphalt one sand process, double asphalt and one sand process, and the premixed process to spread the epoxyemulsified asphalt and emery. The best construction technology is selected through the surface $3 \mathrm{D}$ structure, the change in BPN, and the loss rate of abrasion mass, and its law is analyzed.

\subsection{Experimental Method}

2.3.1. Thermosetting Performance Test. Place the cured epoxy-emulsified asphalt products of different formulations to be studied into an oven at a constant temperature curing. After the epoxy-emulsified asphalt is completely cured $(48 \mathrm{~h})$, place it in an oven at $90^{\circ} \mathrm{C}$ for $1 \mathrm{~h}$ and then remove it. Observe the surface of the sample.

2.3.2. Bonding Performance Test. The research group developed the bond shear strength meter [30] to determine the bond shear strength between epoxy-emulsified asphalt and asphalt mixture specimens of different formulations and selected the best bond shear strength formulation. The normal stress of the interlayer material shear tester is $0.7 \mathrm{MPa}$, the loading rate is $10 \mathrm{~mm} / \mathrm{min}$, and the test temperature is $20^{\circ} \mathrm{C}$. Figure 2 shows the appearance and working principle of the instrument. The test piece was placed in two hollow sleeves of the instrument, the sleeve is a cylinder, the height is $50 \mathrm{~mm}$, and the bottom diameter is $105 \mathrm{~mm}$.

The test steps are described as follows: (1) according to 2.1.3, to form the rut board, use an automatic core drilling machine to remove the core sample of the rut board. Apply $0.5 \mathrm{~kg} / \mathrm{m}^{2}$ of different formula fog sealing asphalt on the surface of the two core samples with structural depth and place it in a $20^{\circ} \mathrm{C}$ constant temperature curing box. Leave it for $1 \mathrm{~h}$, then glue the two cores together and let it stand for $7 \mathrm{~d}$; (2) place the cured test piece in the shearing mold and then place the whole into the sliding rail of the shearing instrument and set the test parameters; (3) turn on the oil pump and the instrument switch to start the test; (4) take out the test piece with a demolding instrument and repeat steps (2) and (3). Figure 3 shows the damaged form of the sample;

(5) according to the calculation method of shear strength 


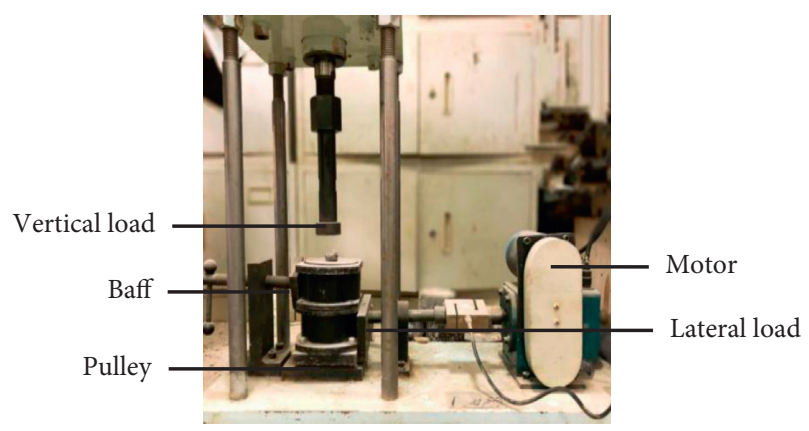

Figure 2: Pavement interlayer material shear tester.

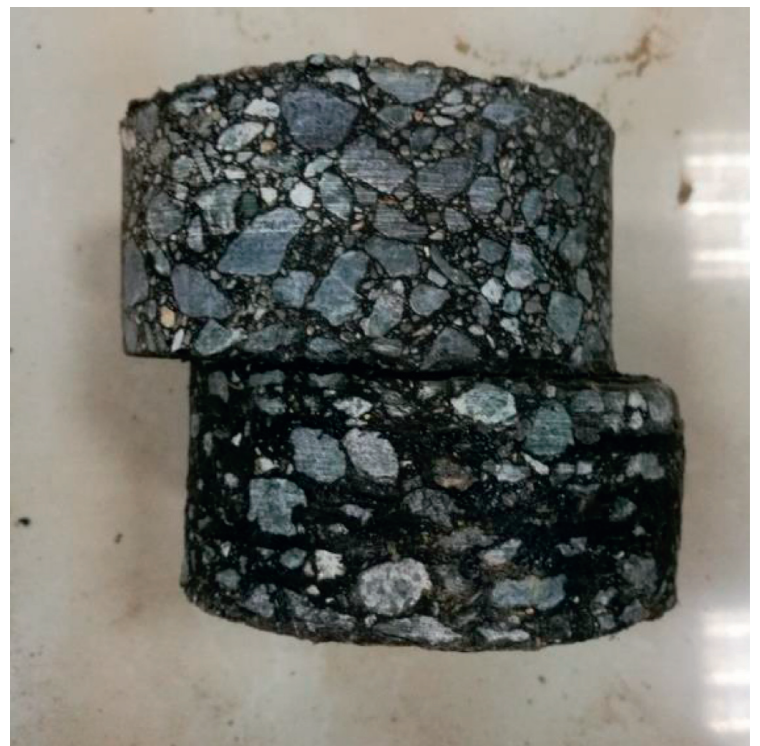

Figure 3: Sample destruction form.

specified in formula (1), the bond shear strength $\tau$ of the fog sealing asphalt is obtained.

$$
\tau_{f}=\frac{F}{S} .
$$

In the formula, $\tau$ is the bonding shear strength (MPa), $\mathrm{F}$ is the shearing force (breaking load), and $S$ is the force area: $S=\pi \times 50.05 \times 50.05=7,870 \mathrm{~mm}^{2}$.

2.3.3. Resistance to High-temperature Water Damage Performance Test. The resistance to high-temperature water damage performance test steps is as follows: (1) prepare the Marshall sample. Weigh $1.0 \mathrm{~kg} / \mathrm{m}^{2}$ of different fog sealing asphalt, evenly apply them on the surface of the Marshall specimens, and place them at room temperature for curing for three-dimensionally to solidify naturally; (2) divide the cured fog-sealed Marshall specimens into two groups. One group evaluates the Marshall stability, and the other group evaluates and calculates the stability of residual water immersion. Figure 4 shows the fog-sealed Marshall sample after fabrication.

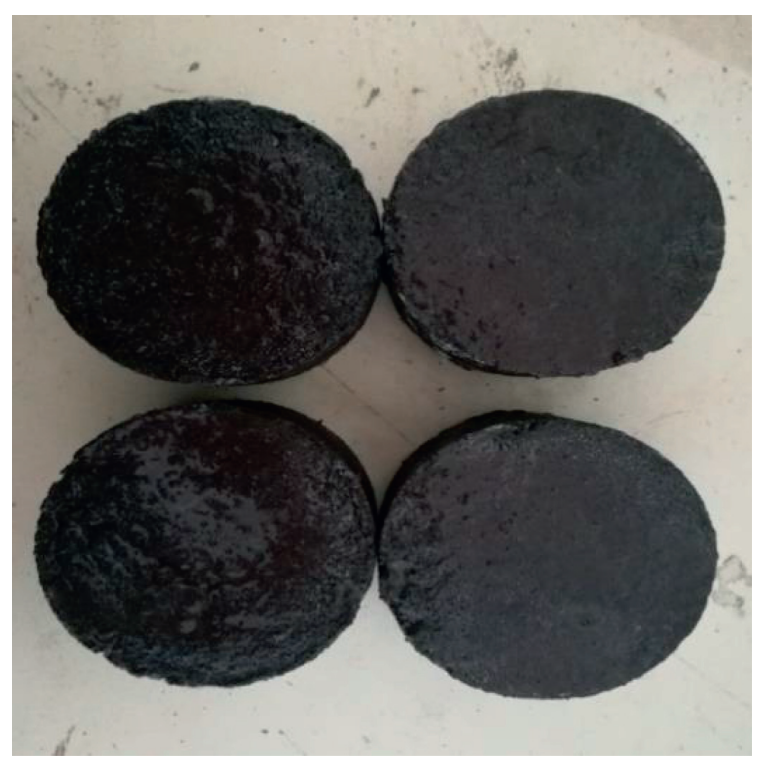

FIGURE 4: Fog-sealed Marshall specimen.

2.3.4. Photothermal Aging Performance Test. The photothermal aging performance test uses a yellowing resistant aging box (Figure 5) independently developed by Chang'an University to simulate the ultraviolet aging radiation in the Loess Plateau of northern Shanxi, China. The test parameters are irradiation intensity $\left(250 \mathrm{~W} / \mathrm{m}^{2}\right)$, temperature $\left(60^{\circ} \mathrm{C}\right)$, and irradiation height $(30 \mathrm{~cm})$ from the aging sample. The aging time is $48 \mathrm{~h}$. According to the ultraviolet irradiance acceleration multiple conversion algorithm, a 48-h indoor ultraviolet irradiation box can simulate the ultraviolet aging of more than $205 \mathrm{~d}$ in northern Shaanxi. The test uses the mass loss rate and appearance of the cured product after $48 \mathrm{~h}$ $\mathrm{UV}$-aging as the evaluation basis using the following formula:

$$
N=\frac{U_{X}}{U}
$$

In the formula, $N$ is the accelerated multiple of ultraviolet irradiation, $U_{X}$ is the irradiation intensity of the aging box $\left(\mathrm{W} / \mathrm{m}^{2}\right)$, and $U$ is the average outdoor daily ultraviolet irradiation $\left(\mathrm{W} / \mathrm{m}^{2}\right)$.

The test steps are as follows: (1) weigh the mass $m_{0}$ of the rotating film-aging test mold, pour the developed epoxyemulsified asphalt, and place it in a thermostat not higher than $40^{\circ} \mathrm{C}$ for curing; (2) when the quality of the sample remains constant, weigh the sample mass $m_{1}$ at this time, open the yellowing resistant ultraviolet aging box, set the temperature in the box to $60^{\circ} \mathrm{C}$, and place four samples for rotating photothermal aging; (3) remove the samples after $48 \mathrm{~h}$ and weigh the mass of the aged samples in $m_{2}$. Convert the mass loss rate of the cured product before and after photothermal aging. The evaluation indicators are as follows: the actual aging status of the emulsified asphalt evaporation residue in the UV-aging box can be divided into four levels, from low to high according to the severity of aging, namely local wrinkles on the surface of the cured material, increased bubbles on the asphalt surface and depression, a large 


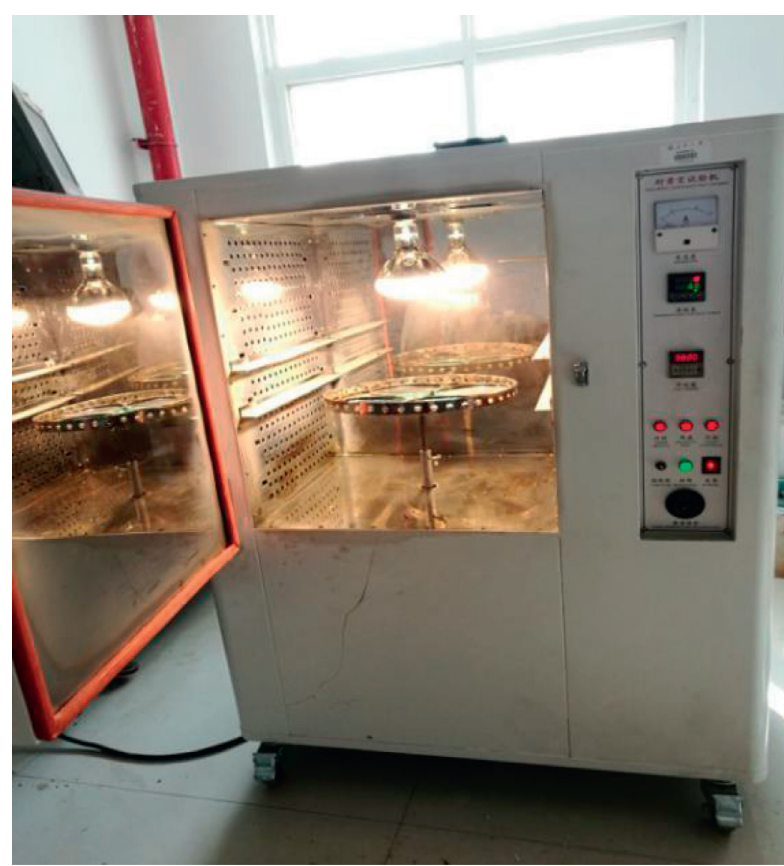

(a)

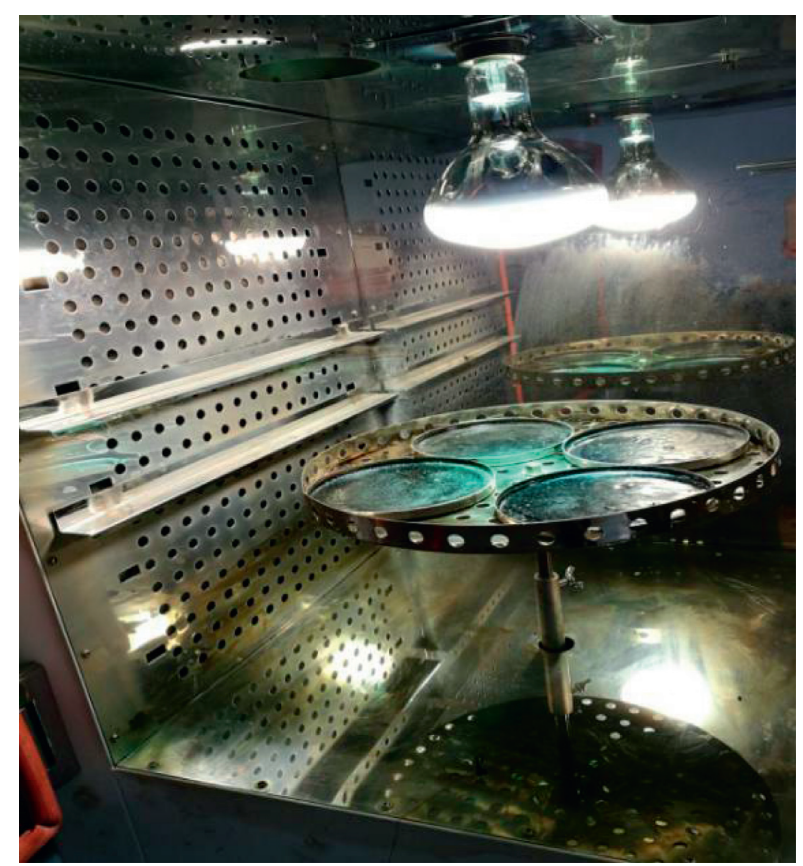

(b)

FIgURE 5: Yellowing resistance aging box: (a) appearance of the box; (b) internal structure.

number of wrinkles and slight wrinkles on the asphalt surface cracks, and large cracks on the asphalt surface causing asphalt fracture [29].

2.3.5. Acceleration Wheel Wear Test. To simulate the abrasion effect of the vehicle while using the skid resistance fog seal, an accelerated abrasion tester (Figure 6) developed by Chang'an University was used. The rotational linear speed of the polyurethane wheel is $84.78 \mathrm{~km} / \mathrm{h}$, which is close to the designed speed of the high-grade highway, and the vertical load is set to $1.4 \mathrm{MPa}[31,32]$.

Acceleration wheel wear test steps are as follows: (1) sequentially measure the pendulum value BPN, the quality of the blank test piece, and the skid resistance fog seal-test sample with the pendulum instrument (Figure 7); (2) place four rut plate test pieces in the installation slot; (3) start the accelerated abrasion test. After the instrument stops rotating, remove the test specimen and measure the BPN of the blank test specimen and the test specimen treated with skidding-resistance and fog sealing at the wear wheel trace and the mass after wear. Figure 8 shows the wear trajectory of the specimen during accelerated wear.

The evaluation indicators are described. Figure 8 shows the simplified model of the wheel trace after the four rut plate specimens wear, and the BPN on the wear track is measured. The BPN of the skid resistance fog seal sample under a certain amount of wear expresses the skid resistance performance under this amount of wear. The BPN drop of the skid resistance fog seal sample under a certain amount of wear shows that the skid resistance fog seal layer evaluated the skid resistance durability. Therefore, the larger the BPN value in the wear process, the better the skid resistance

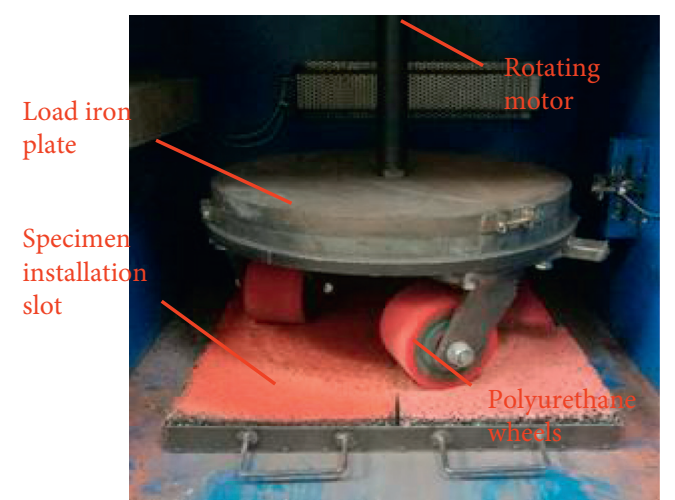

Figure 6: Accelerated wear tester.

performance, the slower the BPN decline, and the better the skid resistance durability $[33,34]$. Combined with the mass loss rate of the specimen after 100,000 abrasions, the durability of the skid resistance fog seal was evaluated comprehensively.

See formula (3) for the calculation of the mass loss rate.

$$
V_{1}=\frac{m_{0}-m_{1}}{m_{b}-m_{a}} \times \frac{A}{A_{1}} .
$$

In the formula, $V_{1}$ is the mass loss rate of the test specimen (\%), $m_{0}$ is the mass of the specimen before abrasion (g), $m_{1}$ is the mass of the specimen after abrasion (g), $m_{a}$ is the skid resistance fog seal is not spread the mass of the specimen $(\mathrm{g}), m_{b}$ is the mass of the specimen after the skid resistance fog seal layer is cured $(\mathrm{g}), A$ is the area of the specimen $\left(A=900 \mathrm{~cm}^{2}\right)$, and $A_{1}$ is the abrasion area of the specimen $\left(A_{1}=204.88 \mathrm{~cm}^{2}\right)$. 


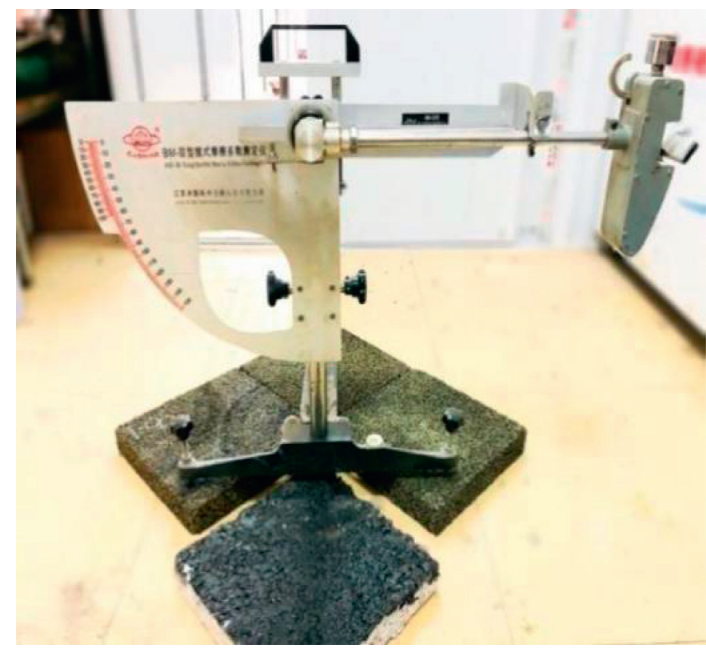

FIgURE 7: British pendulum tester.

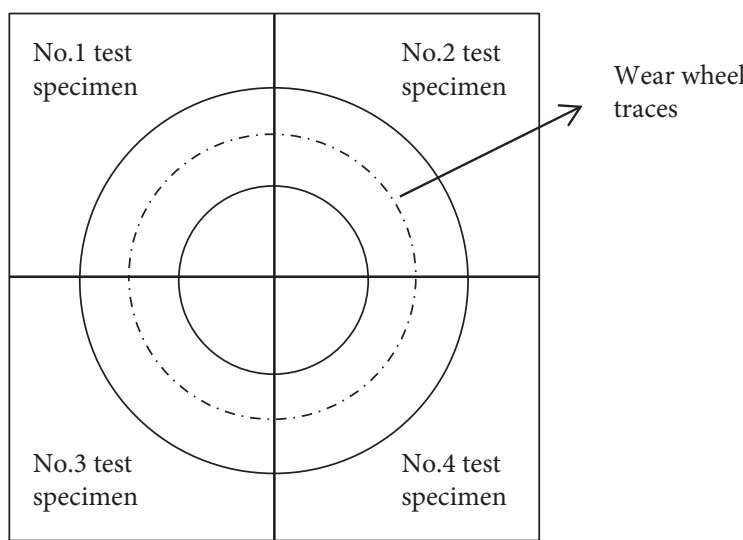

FIgURE 8: Wear track of specimen during accelerated wear.

\subsubsection{Test Method of Construction Technology}

(1) One Oil and One Sand Process. When the sample is formed using the one oil and one sand process, the spraying device sprays the designed amount of fog sealing asphalt on the rut plate, and the corresponding amount of emery is used. After molding, the sample is placed in a $30^{\circ} \mathrm{C}$ blast box to keep the temperature constant. The surface is dry, and Figure 9 shows the shape and surface structure of the oneoil-one-sand specimen.

(2) Double Oil and One Sand Process. When the sample is formed using the double oil and one sand process, the spraying device sprays half of the designed amount of fog sealing asphalt on the rut plate, and sprinkle emery. After the surface of the sample is dry, the remaining part is sprayed with epoxy-emulsified asphalt. The test specimen is placed in a $30^{\circ} \mathrm{C}$ blast box at a constant temperature until the surface of the test piece is dry. Figure 10 shows the shape and surface structure of the double asphalt and one sand test specimen.

(3) Premixed Process. When forming the test specimen in the premixing process chamber, weigh the epoxy-emulsified

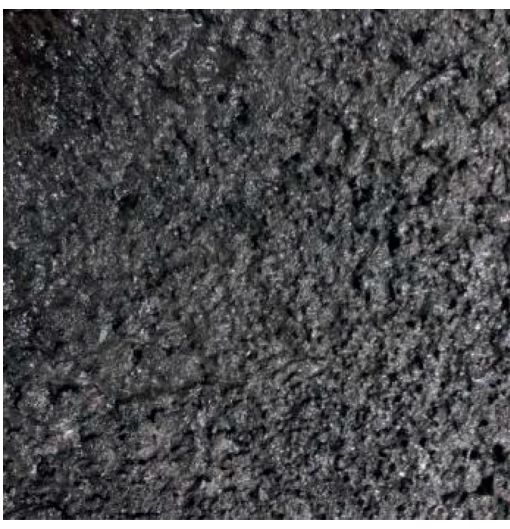

Figure 9: One asphalt one sand.

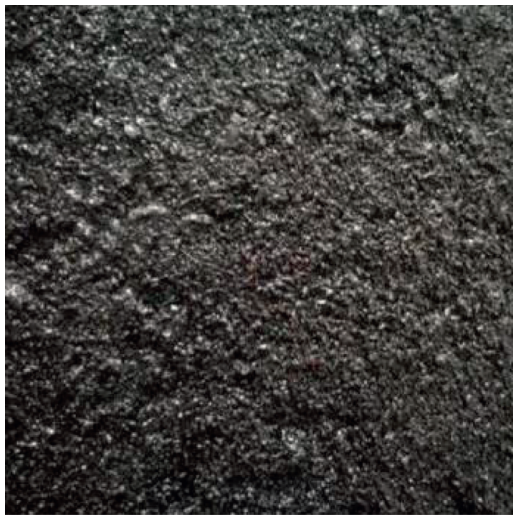

FIGURE 10: Double asphalt one sand.

asphalt and emery in proportion, mix them well to form a mortar mixture, spread it evenly on the rut board, and use a scraper and other auxiliary tools to pave it evenly. Figure 11 shows the forming diagram and surface structure of the premix process specimen.

\section{Results and Discussion}

3.1. Preliminary Selection of the Fog Sealing Asphalt Material Ratio. The instructions for curing agent $\mathrm{A}$ show that the mass ratio of water-based epoxy resin emulsion and curing agent $\mathrm{A}$ ranges from $2: 1$ to $4: 1$.

In the epoxy resin emulsified asphalt, when the asphalt component content exceeds $50 \%$, the overall performance of the material approaches the asphalt property, and the fracture resistance is significantly improved. When the epoxy system component is higher than $50 \%$, the overall resin is the matrix and the material is susceptible to tensile fracture [29, 30]. For pavement spray materials, once the proportion of epoxy system components (water-based epoxy resin emulsion and water-based curing agent) exceeds $50 \%$, the cured product of epoxy-emulsified asphalt has a significant thermosetting and increased brittleness, causing it to break easily under the action of external factors and peels off from the surface layer. Therefore, it is unsuitable to be used as a pavement fog sealing asphalt. Given this, the test 


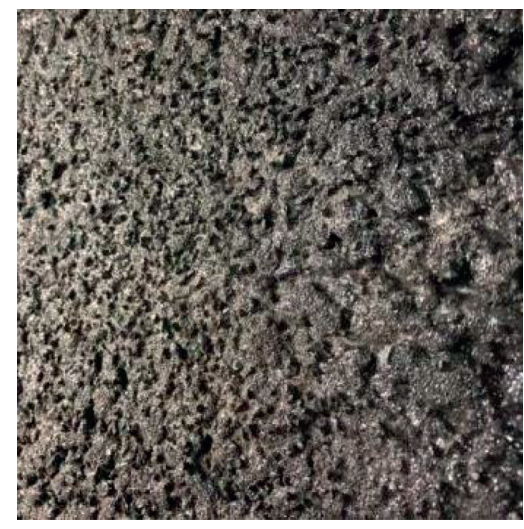

Figure 11: Premix process.

determined the mass range of the emulsified asphalt component in the epoxy-emulsified asphalt to be $50 \%-90 \%$ of the total mass. In the epoxy system components, the mass ratio of the water-based epoxy resin emulsion to the waterbased curing agent was $2: 1-4: 1$.

To determine the range of epoxy-emulsified asphalt formulations, different formulations of epoxy-emulsified asphaltcured products were used and put into an oven for constant temperature curing. After the epoxy-emulsified asphalt is completely cured, place it in an oven at $90^{\circ} \mathrm{C}$ and bake it for $1 \mathrm{~h}$. The thermosetting test results are shown in Table 6.

Table 6 shows that after the cured product is baked, the samples with the formula codes $A_{50}\left(E_{2}\right), A_{50}\left(E_{3}\right)$, and $\mathrm{A}_{50}\left(\mathrm{E}_{4}\right)$ are thermosetting. When the cured product's asphalt component mass accounts for no less than $60 \%$ of the total mass, as the proportion of the asphalt component increases and the ratio of the two components of the epoxy system increases, the cured product has a transformation tendency from thermosetting to thermoplastics.

Therefore, follow-up tests are screened in the range of $A_{i}\left(E_{j}\right)$ $\{i=60,70,80,90 ; j=2,3,4\}$, combined with the bonding and aging performance of the fog sealing asphalt. The performance of high-temperature water damage resistance comprehensively determines the best formula of fog sealing asphalt.

\subsection{Optimum Ratio of Fog Sealing Asphalt}

3.2.1. Bond Performance Test Results. Table 7 and Figure 12 show the test results of the bond shear strength of epoxyemulsified asphalt with different formulations and common asphalt for fog seal.

Table 7 and Figure 12 show that when the ratio of the two components of the epoxy system is constant, with the increase in the asphalt component content, the adhesive shear strength of epoxy-emulsified asphalt will first increase and then decrease. And when the asphalt component reaches $75 \%$, the adhesive shear strength of epoxy-emulsified asphalt will become higher than that of common asphalt for fog seal. When the asphalt component increases to $80 \%$, the bonding shear strength of epoxy-emulsified asphalt reaches its peak. Among them, $\mathrm{A}_{80}\left(\mathrm{E}_{3}\right)>\mathrm{A}_{80}\left(\mathrm{E}_{2}\right)>\mathrm{A}_{80}\left(\mathrm{E}_{4}\right)$. The adhesive shear strength of epoxy-emulsified asphalt with sample numbers $A_{80}\left(E_{3}\right), A_{80}\left(E_{2}\right)$, and $A_{80}\left(E_{4}\right)$ is increased by $21 \%$,
$18 \%$, and $16 \%$, respectively, compared with the commonly used asphalt for fog seals.

Based on the best consideration of bonding performance, the epoxy-emulsified asphalt formulations numbered $A_{80}\left(E_{3}\right), A_{80}\left(E_{2}\right)$, and $A_{80}\left(E_{4}\right)$ are adopted.

\subsubsection{High-Temperature Water Damage Test Results.} Table 8 shows the test results of residual immersion stability of different fog seal Marshall specimens.

As can be seen from Table 8, the change in the ratio of the two components of the epoxy system has a specific impact on the residual stability of the mist seal Marshall specimens, but the impact is lower than the change in the quality of the asphalt components. When the asphalt component content is $80 \%$, the fog seal Marshall specimen has the largest increase than the blank specimen. Among them, the fog seal asphalt under $A_{80}\left(E_{2}\right)$ has the best high-temperature water damage resistance, and the residual stability of the specimen is comparable with the blank sample; it is increased by $13 \%$.

\subsubsection{Resistance to Aging Performance Test Results}

(1) The Quality Loss Rate of the Cured Product. Figure 13 shows the mass loss rate of the cured product of the epoxy-emulsified fog seal asphalt after 48 -h photothermal aging. The mass loss rate of commonly used asphalt for fog seal is $5.7 \%$.

Figure 13 shows that when the asphalt component content is greater than $80 \%$, the increase in the asphalt component and the ratio of the two components of the epoxy system will reduce the mass loss rate of the cured product after $48 \mathrm{~h} \mathrm{UV}$-aging, and both are lower than those commonly used in fog seals. For the asphalt quality loss rate, $\mathrm{A}_{90}\left(\mathrm{E}_{2}\right)<\mathrm{A}_{90}\left(\mathrm{E}_{3}\right)<\mathrm{A}_{90}\left(\mathrm{E}_{4}\right)<\mathrm{A}_{80}\left(\mathrm{E}_{2}\right)<\mathrm{A}_{80}\left(\mathrm{E}_{3}\right)$. The mass loss rate of $\mathrm{A}_{90}\left(\mathrm{E}_{2}\right)$ is $3.09 \%$, which is the smallest among all $\mathrm{UV}$-aging samples.

(2) Aging Appearance Classification. According to the UVaging classification method of the evaporation residue of emulsified asphalt, the light and heat aging resistance of the cured epoxy-emulsified asphalt of different formulations is analyzed. Figure 14 shows the appearance and morphology, and Table 9 shows the aging classification results based on the appearance and morphology.

(3) Formula Selection of Aging Resistance Fog Seal Asphalt. Combining the two indicators of the quality loss rate of the cured product and the appearance-aging evaluation, the fog seal asphalt formula with better aging resistance is $\mathrm{A}_{90}\left(\mathrm{E}_{2}\right)$, $\mathrm{A}_{90}\left(\mathrm{E}_{3}\right), \mathrm{A}_{90}\left(\mathrm{E}_{4}\right)$, and $\mathrm{A}_{80}\left(\mathrm{E}_{2}\right)$.

\subsubsection{The Best Formulation of Epoxy-Emulsified Asphalt as a} Fog Seal Asphalt. Combined with research on epoxyemulsified asphalt bonding performance, high-temperature water damage resistance, and light and heat aging resistance, the best formulation for epoxy-emulsified asphalt is selected as the fog seal asphalt. Table 10 shows the best formulations of various properties, and that by combining the three 
TABLE 6: Thermosetting grade of cured product.

\begin{tabular}{|c|c|c|c|c|c|}
\hline Formula code & $\mathrm{A}_{50}\left(\mathrm{E}_{2}\right)$ & $\mathrm{A}_{60}\left(\mathrm{E}_{2}\right)$ & $\mathrm{A}_{70}\left(\mathrm{E}_{2}\right)$ & $\mathrm{A}_{80}\left(\mathrm{E}_{2}\right)$ & $\mathrm{A}_{90}\left(\mathrm{E}_{2}\right)$ \\
\hline $\begin{array}{l}\text { Thermoset } \\
\text { performance }\end{array}$ & $\begin{array}{c}\text { No } \\
\text { change }\end{array}$ & $\begin{array}{l}\text { Surface slightly } \\
\text { flows }\end{array}$ & Surface flows & $\begin{array}{l}\text { Flowing occurs above the } \\
\text { middle }\end{array}$ & The whole is flowing \\
\hline Formula code & $\mathrm{A}_{50}\left(\mathrm{E}_{3}\right)$ & $\mathrm{A}_{60}\left(\mathrm{E}_{3}\right)$ & $\mathrm{A}_{70}\left(\mathrm{E}_{3}\right)$ & $\mathrm{A}_{80}\left(\mathrm{E}_{3}\right)$ & $\mathrm{A}_{90}\left(\mathrm{E}_{3}\right)$ \\
\hline $\begin{array}{l}\text { Thermoset } \\
\text { performance }\end{array}$ & $\begin{array}{l}\text { No } \\
\text { change }\end{array}$ & Surface flows & Partly flowing & Most of it is flowing & The whole is flowing \\
\hline Formula code & $\mathrm{A}_{50}\left(\mathrm{E}_{4}\right)$ & $\mathrm{A}_{60}\left(\mathrm{E}_{4}\right)$ & $\mathrm{A}_{70}\left(\mathrm{E}_{4}\right)$ & $\mathrm{A}_{80}\left(\mathrm{E}_{4}\right)$ & $\mathrm{A}_{90}\left(\mathrm{E}_{4}\right)$ \\
\hline $\begin{array}{l}\text { Thermoset } \\
\text { performance }\end{array}$ & $\begin{array}{c}\text { No } \\
\text { change }\end{array}$ & Surface flows & $\begin{array}{l}\text { Flowing occurs above the } \\
\text { middle }\end{array}$ & Most of it is flowing & The whole is flowing \\
\hline
\end{tabular}

TABLE 7: Bond shear strength.

\begin{tabular}{|c|c|c|c|c|c|}
\hline Formula code & $\mathrm{A}_{70}\left(\mathrm{E}_{2}\right)$ & $\mathrm{A}_{75}\left(\mathrm{E}_{2}\right)$ & $\mathrm{A}_{80}\left(\mathrm{E}_{2}\right)$ & $\mathrm{A}_{85}\left(\mathrm{E}_{2}\right)$ & $\mathrm{A}_{90}\left(\mathrm{E}_{2}\right)$ \\
\hline$F(\mathrm{kN})$ & 3.31 & 4.41 & 5.20 & 4.88 & 4.72 \\
\hline$\tau_{f}(\mathrm{MPa})$ & 0.42 & 0.56 & 0.66 & 0.62 & 0.60 \\
\hline Formula code & $\mathrm{A}_{70}\left(\mathrm{E}_{3}\right)$ & $\mathrm{A}_{75}\left(\mathrm{E}_{3}\right)$ & $\mathrm{A}_{80}\left(\mathrm{E}_{3}\right)$ & $\mathrm{A}_{85}\left(\mathrm{E}_{3}\right)$ & $\mathrm{A}_{90}\left(\mathrm{E}_{3}\right)$ \\
\hline$F(\mathrm{kN})$ & 3.54 & 4.72 & 5.35 & 4.96 & 4.71 \\
\hline$\tau_{f}(\mathrm{MPa})$ & 0.45 & 0.60 & 0.68 & 0.63 & 0.60 \\
\hline Formula code & $\mathrm{A}_{70}\left(\mathrm{E}_{4}\right)$ & $\mathrm{A}_{75}\left(\mathrm{E}_{4}\right)$ & $\mathrm{A}_{80}\left(\mathrm{E}_{4}\right)$ & $\mathrm{A}_{85}\left(\mathrm{E}_{4}\right)$ & $\mathrm{A}_{90}\left(\mathrm{E}_{4}\right)$ \\
\hline$F(\mathrm{kN})$ & 3.93 & 4.49 & 5.12 & 4.72 & 4.56 \\
\hline$\tau_{f}(\mathrm{MPa})$ & 0.50 & 0.57 & 0.65 & 0.60 & 0.58 \\
\hline Formula code & \multirow{2}{*}{\multicolumn{5}{|c|}{$\begin{array}{l}\text { Commonly used asphalt for fog seal } \\
4.41\end{array}$}} \\
\hline$F(\mathrm{kN})$ & & & & & \\
\hline$\tau_{f}(\mathrm{MPa})$ & & & 0.55 & & \\
\hline
\end{tabular}

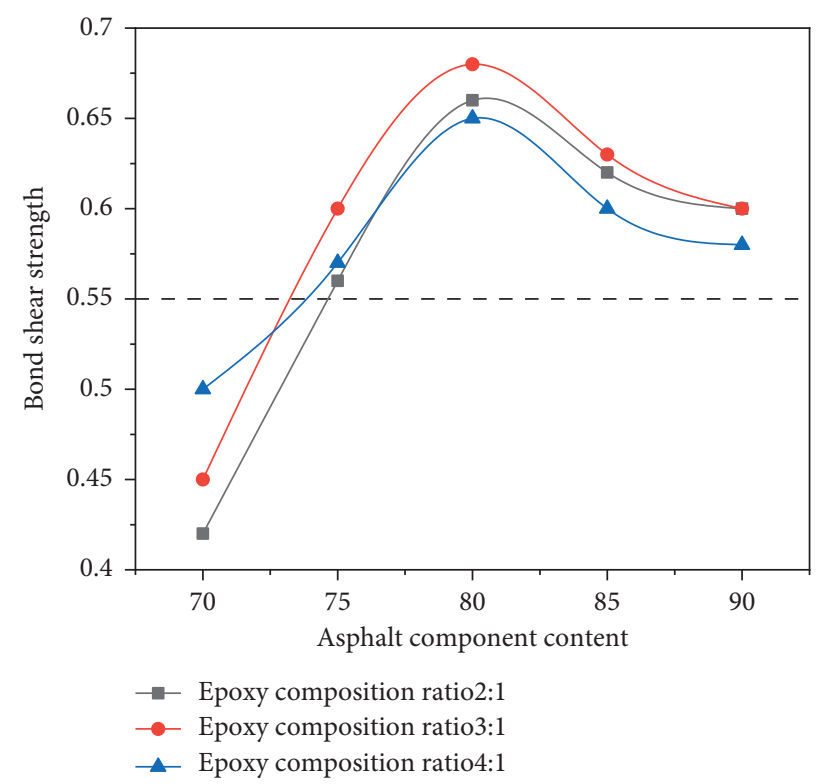

FIGURE 12: Cohesive shear strength of epoxy-emulsified asphalt.

TABLE 8: Immersion residual stability of fog seal Marshall specimens.

\begin{tabular}{lccccccc}
\hline Formula code & $\mathrm{A}_{60}\left(\mathrm{E}_{2}\right)$ & $\mathrm{A}_{60}\left(\mathrm{E}_{3}\right)$ & $\mathrm{A}_{60}\left(\mathrm{E}_{4}\right)$ & $\mathrm{A}_{70}\left(\mathrm{E}_{2}\right)$ & $\mathrm{A}_{70}\left(\mathrm{E}_{3}\right)$ & $\mathrm{A}_{70}\left(\mathrm{E}_{4}\right)$ & Blank specimen \\
\hline $\mathrm{MS}_{0}(\%)$ & 93.3 & 93.9 & 93.9 & 90.1 & 93.0 & 93.2 & 86.6 \\
$\mathrm{MS}_{0} / 86.6$ & 1.07 & 1.08 & 1.08 & 1.04 & 1.07 & 1.08 & 1 \\
\hline Formula code & $\mathrm{A}_{80}\left(\mathrm{E}_{2}\right)$ & $\mathrm{A}_{80}\left(\mathrm{E}_{3}\right)$ & $\mathrm{A}_{80}\left(\mathrm{E}_{4}\right)$ & $\mathrm{A}_{90}\left(\mathrm{E}_{2}\right)$ & $\mathrm{A}_{90}\left(\mathrm{E}_{3}\right)$ & $\mathrm{A}_{90}\left(\mathrm{E}_{4}\right)$ & Commonly used asphalt for fog seal \\
\hline $\mathrm{MS}_{0}(\%)$ & 97.7 & 96.4 & 95.0 & 89.0 & 87.6 & 88.3 & 91.6 \\
$\mathrm{MS}_{0} / 86.6$ & 1.13 & 1.10 & 1.09 & 1.03 & 1.00 & 1.02 & 1.06 \\
\hline
\end{tabular}




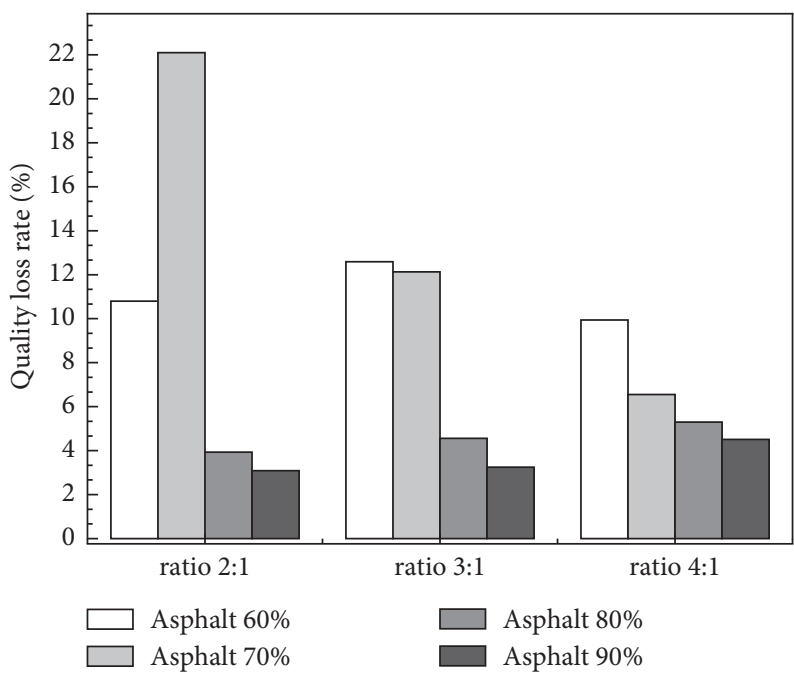

FIGURE 13: The mass loss rate of cured products after photothermal aging.

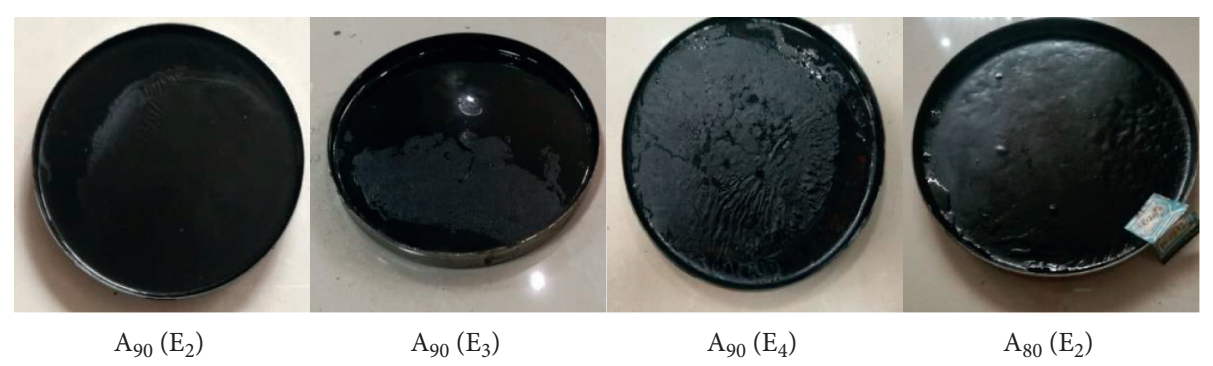

(a)

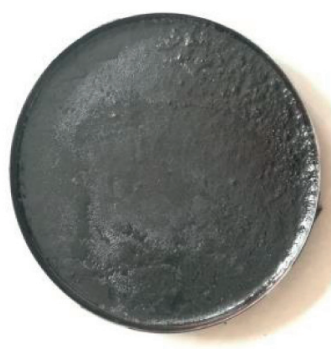

$\mathrm{A}_{80}\left(\mathrm{E}_{3}\right)$

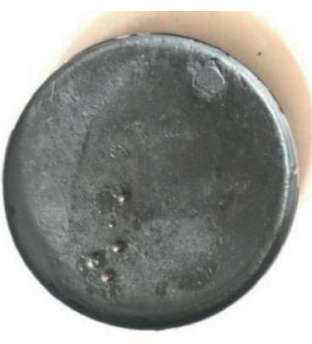

$\mathrm{A}_{70}\left(\mathrm{E}_{3}\right)$

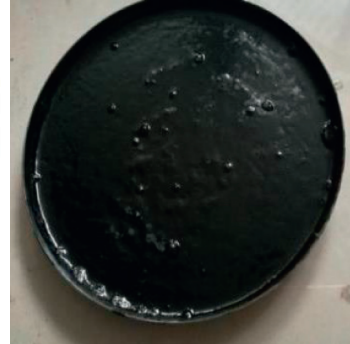

$\mathrm{A}_{60}\left(\mathrm{E}_{2}\right)$

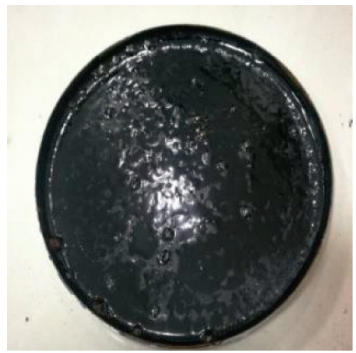

$\mathrm{A}_{80}\left(\mathrm{E}_{4}\right)$

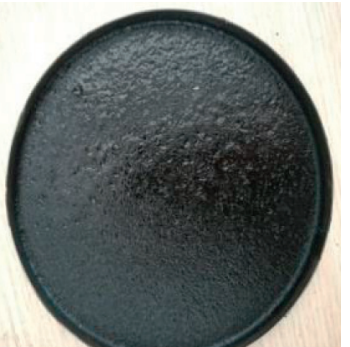

Commonly-used asphalt for fog seal

(b)

FIgURe 14: Continued. 


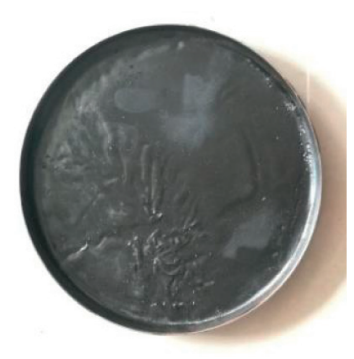

$\mathrm{A}_{60}\left(\mathrm{E}_{3}\right)$

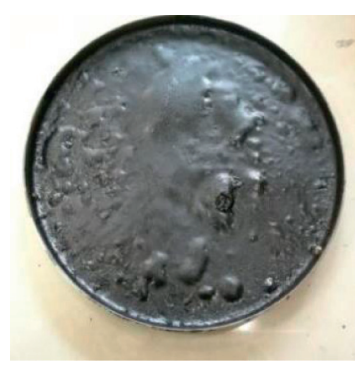

$\mathrm{A}_{70}\left(\mathrm{E}_{4}\right)$

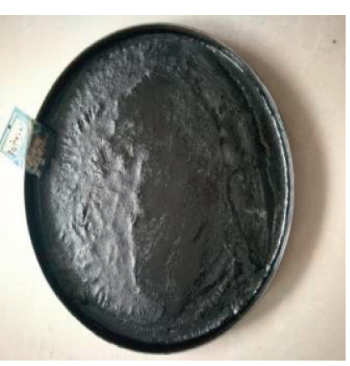

$\mathrm{A}_{60}\left(\mathrm{E}_{4}\right)$

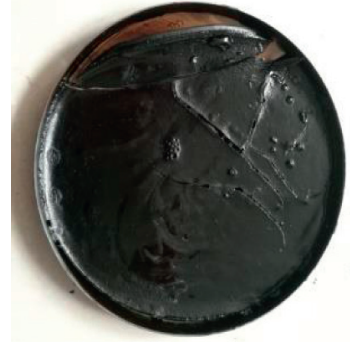

$\mathrm{A}_{70}\left(\mathrm{E}_{2}\right)$

(d)

FIGURE 14: The morphology of the cured product of the fog seal asphalt after photothermal aging. (a) Level I aging (small wrinkles and bubbles). (b) Level II aging (significant bubbles, surface depression). (c) Level III aging (large folds). (d) Level IV aging (fracture).

TABLE 9: Photothermal aging status.

\begin{tabular}{lc}
\hline Aging condition & Cured type \\
\hline Level I & $\mathrm{A}_{90}\left(\mathrm{E}_{2}\right)<\mathrm{A}_{90}\left(\mathrm{E}_{3}\right)<\mathrm{A}_{90}\left(\mathrm{E}_{4}\right)<\mathrm{A}_{80}\left(\mathrm{E}_{2}\right)$ \\
Level II & $\mathrm{A}_{80}\left(\mathrm{E}_{3}\right)<\mathrm{A}_{70}\left(\mathrm{E}_{3}\right)<\mathrm{A}_{60}\left(\mathrm{E}_{2}\right)<\mathrm{A}_{80}\left(\mathrm{E}_{4}\right)<$ Commonly used asphalt for fog seal \\
Level III & $\mathrm{A}_{60}\left(\mathrm{E}_{3}\right)<\mathrm{A}_{70}\left(\mathrm{E}_{4}\right)<\mathrm{A}_{60}\left(\mathrm{E}_{4}\right)$ \\
Level IV & $\mathrm{A}_{70}\left(\mathrm{E}_{2}\right)$ \\
\hline
\end{tabular}

TABLE 10: Optimal formula for various performance.

\begin{tabular}{lr}
\hline Fog seal asphalt performance & Epoxy emulsified asphalt formula \\
\hline Bonding performance & $\mathrm{A}_{80}\left(\mathrm{E}_{3}\right) ; \mathrm{A}_{80}\left(\mathrm{E}_{2}\right) ; \mathrm{A}_{80}\left(\mathrm{E}_{4}\right)$ \\
High-temperature water damage performance & $\mathrm{A}_{80}\left(\mathrm{E}_{2}\right) ; \mathrm{A}_{80}\left(\mathrm{E}_{3}\right) ; \mathrm{A}_{60}\left(\mathrm{E}_{3}\right) ; \mathrm{A}_{70}\left(\mathrm{E}_{4}\right)$ \\
Aging resistance performance & $\mathrm{A}_{90}\left(\mathrm{E}_{2}\right) ; \mathrm{A}_{90}\left(\mathrm{E}_{3}\right) ; \mathrm{A}_{90}\left(\mathrm{E}_{4}\right) ; \mathrm{A}_{80}\left(\mathrm{E}_{2}\right)$ \\
\hline
\end{tabular}

properties, epoxy-emulsified asphalt formula $A_{80}\left(E_{2}\right)$ is the most suitable as a fog sealing asphalt.

\subsection{Influence of the Ratio of the Number of Skid Resistance} Particles to the Amount of Fog Seal Asphalt for the Skid Resistance Durability of the Skid Resistance Fog Seal Layer. Take the amount of epoxy-emulsified asphalt to be $0.6 \mathrm{~kg} / \mathrm{m}^{2}$. Table 11 shows the proportion of emery content to epoxyemulsified asphalt and the amount of emery spreading.

Figure 15 shows the BPN change rule of the fog seal-test specimen formed in different proportions of emery content and epoxy-emulsified asphalt content during the wear process. Figure 16 shows the mass loss rate of the test piece after 100,000 times abrasion.

It can be seen from Figures 15 and 16 that the wear times BPN curves of the molded specimens in varying proportions first decrease rapidly and then tend to be flat. As the proportion increases, the mass loss of the skid resistance fog seal specimens' first decreases and then increases rapidly. Among the five ratios studied, the initial BPN value of the fog seal layer sample decreases with the increase in the ratio, that is, when the ratio of the two is $4: 6$, the initial skid resistance performance is the best. As the number of wear increases, when the ratio is $1: 1$, the BPN curve of the abraded skid resistance fog seal specimen is at the top, and the skid resistance durability is the best. When the ratio is small, the epoxy-emulsified asphalt does not adequately wrap the emery, resulting in a significant increase in the surface roughness of the unwearied test piece. However, because of insufficient adhesion between the whole skid resistance fog seal and the test specimen, it is easy to wear out and BPN decreases rapidly during the wear process. When the ratio is large, the skid resistance effect of emery is weakened because of the over-wrapping of epoxy-emulsified asphalt, the skid resistance fog seal layer wears seriously under the action of the wheel rolling, and the BPN decreases rapidly. When the ratio is close to $1: 1$, the emery is fully and uniformly covered by the epoxy-emulsified asphalt, and the surface structure is gradually filled. After repeated abrasions, it shows the best skid resistance performance. What is more, after 100,000 abrasions, the BPN values of the five specimens were reduced by $33.8,35.1,27.4,31.0$, and $28.2 \%$. When the ratio was $1: 1$, the BPN decrease was the smallest. Similar to the BPN law, the mass loss rate curve reaches a minimum of $58.9 \%$ near the ratio of $1: 1$.

In summary, when the proportion of emery and epoxyemulsified asphalt is $1: 1$, the skid resistance durability of the fog seal is the best.

3.4. Influence of the Total Amount of Skid Resistance Fog Sealing Asphalt on the Skid Resistance Durability of the Skid Resistance Fog Seal Layer. Section 3.3 explained that when 
TABLE 11: The ratio of the amount of emery to the amount of epoxy emulsified asphalt and the amount of emery spreading in the skid resistance fog seal-test specimen.

\begin{tabular}{lccccc}
\hline The ratio of emery content to epoxy emulsified asphalt & $4: 6$ & $5: 6$ & $1: 1$ & $7: 6$ & $8: 6$ \\
\hline Emery content $\left(\mathrm{kg} / \mathrm{m}^{2}\right)$ & 0.4 & 0.5 & 0.6 & 0.7 & 0.8 \\
Total amount of emery $(\mathrm{g})$ & 36 & 45 & 54 & 63 \\
\hline
\end{tabular}

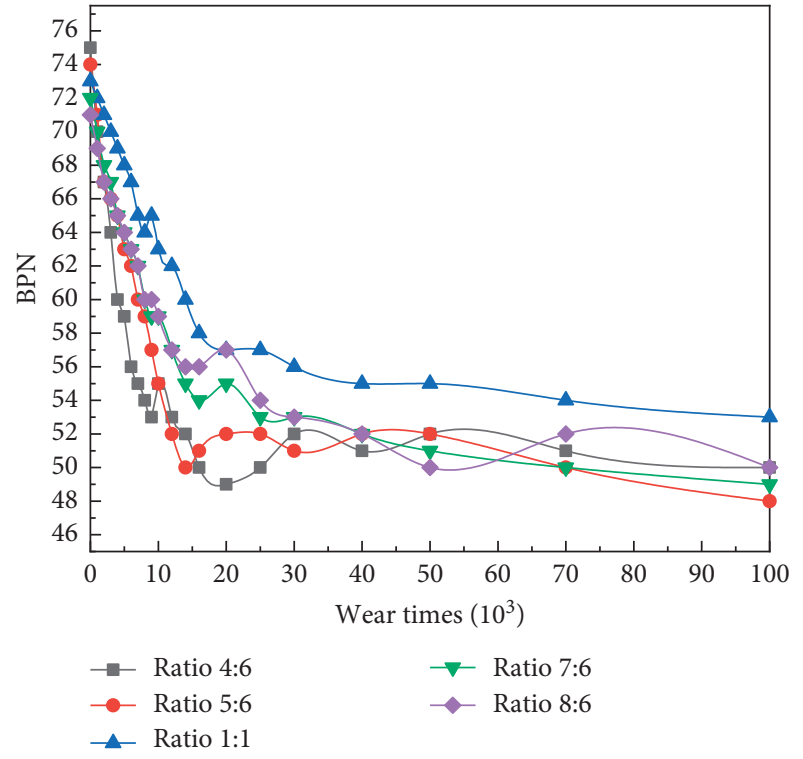

FIgURE 15: BPN abrasion law of specimens.

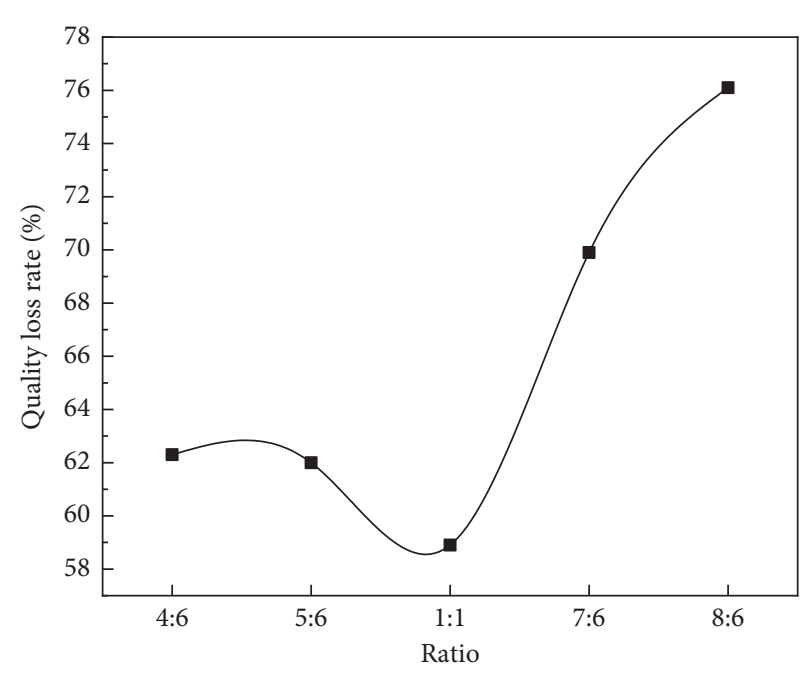

FIgURE 16: Mass loss rate of specimens.

the ratio of emery content to epoxy-emulsified asphalt is selected at $1: 1$, it can ensure better antiskid durability. This section, according to the change in the total amount of skid resistance fog sealing asphalt, calculates the required optimal skid resistance particle content and the amount of fog seal material used in each skid resistance fog seal-test specimen according to the ratio $1: 1$, as shown in Table 12 .

Figure 17 shows the variation in BPN of epoxy-emulsified asphalt skid resistance fog seal-test specimens formed with the different total amount of skid resistance fog seal asphalt during accelerated wear. Figure 18 shows the mass loss rate of the test specimens after 100,000 abrasions.

As can be seen From Figures 17 and 18 that the abrasion times BPN curves of the total amount of different skid resistance fog seal asphalt drop rapidly and then tend to be flat. With the increase in the total amount of skid resistance fog seal asphalt, the mass loss of the specimen wear first decreases and then increases. In the five types of skid resistance fog sealing asphalt materials studied, the initial BPN value of the test specimen decreases with the increase in the total amount. When the amount of skid resistance fog sealing asphalt is $0.8 \mathrm{~kg} / \mathrm{m}^{2}$, the initial skid resistance performance is the best. As the number of wear increases, the BPN curve with a $1.2 \mathrm{~kg} / \mathrm{m}^{2}$ of skid resistance fog sealing asphalt is at the top, and the skid resistance durability is the best. Although the proportion of emery and epoxy-emulsified asphalt is the same, when the total amount is smaller, emery penetrates the thinner skid resistance fog seal layer and the height of emery particles on the surface of the skid resistance fog seal is larger, causing its initial antiskid performance to be high. As the number of wear increases, the convex emery of the skid resistance fog seal with a smaller total amount has a smaller bond with the epoxy-emulsified asphalt, causing the emery to be easily worn off during the abrasion process, and the BPN decreases rapidly [35].

In addition, the most representative specimen is $0.8 \mathrm{~kg} / \mathrm{m}^{2}$. When it is worn out $80,000-90,000$ times, the emery is first worn away. The BPN value in the early stage drops rapidly, and the epoxy-emulsified asphalt is almost completely worn out. The original surface of the test specimens is exposed, so the BPN is slightly improved in the later period. When the total amount is large, the emery is completely suspended in the epoxy-emulsified asphalt, producing a thicker oil film on the surface of the skid resistance fog seal layer, weakening the skid resistance performance, and the $\mathrm{BPN}$ is always small. When the dosage is $1.2 \mathrm{~kg} / \mathrm{m}^{2}$, the thickness of the skid resistance fog seal layer is moderate, the height of the emery bulge is moderate, and the bond between emery and epoxy-emulsified asphalt is good. Therefore, BPN is the largest, and it shows the best skid resistance performance and durability performance after repeated abrasion. What is more, the BPN of the five specimens decreased by $37.3 \%, 34.2 \%, 27.4 \%, 28.8 \%$, and $32.4 \%$ after 100,000 abrasions. Among them, when the total amount of skid resistance fog sealing asphalt is $1.2 \mathrm{~kg} / \mathrm{m}^{2}$, the BPN decrease is the smallest. The result is similar when the total amount of antiskid fog seal cement is $1.2 \mathrm{~kg} / \mathrm{m}^{2}$, the mass loss rate reaches the minimum $58.9 \%$, showing the best skid resistance durability.

In summary, when the total dosage is $1.2 \mathrm{~kg} / \mathrm{m}^{2}$, the skid resistance fog seal layer exhibits better skid resistance durability. 
TABLE 12: The dosage and total dosage of each material component of skid resistance fog seal asphalt.

Each material component of skid resistance fog seal asphalt

\begin{tabular}{|c|c|c|c|c|c|}
\hline & 0.4 & 0.5 & 0.6 & 0.7 & 0.8 \\
\hline Epoxy-emulsified asphalt & 36 & 45 & 54 & 63 & 72 \\
\hline Emery & 36 & 45 & 54 & 63 & 72 \\
\hline Total amount of materials & 72 & 90 & 108 & 126 & 144 \\
\hline
\end{tabular}
asphalt material $\left(\mathrm{kg} / \mathrm{m}^{2}\right)$

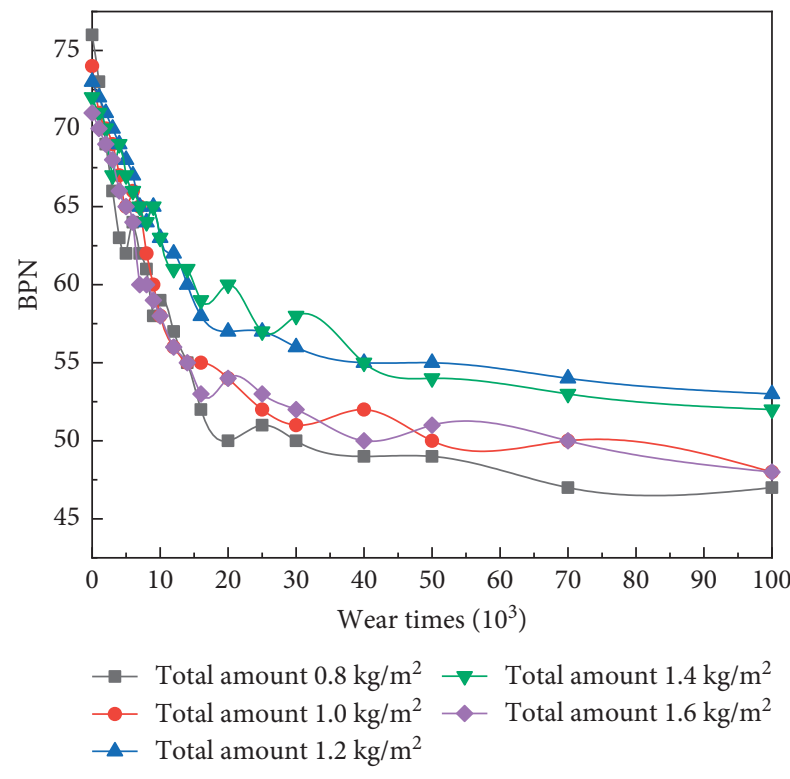

FIgURE 17: BPN abrasion law of specimens.

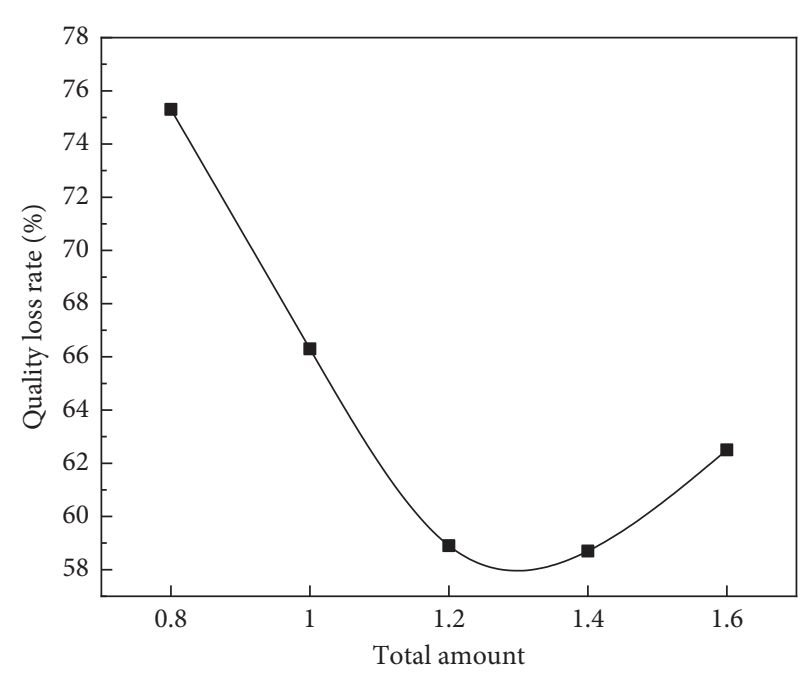

FIGURE 18: Mass loss rate of specimens.

\subsection{Influence of the Construction Process on the Performance of the Skid Resistance Fog Seal}

3.5.1. Surface $3 D$ Structure. The cured surface of the skid resistance fog seal-test specimens paved by the one asphalt one sand process, the double asphalt one sand process, and the premix process are captured by a camera and imported
The amount of each material component of the test specimen $(g)$ when the total amount of the following skid resistance fog seal

into Image-Pro Plus software for grayscale. The 3D structure map is derived from chemical processing [36], and the depth and uniformity of the surface structure are used to evaluate the impact of the three construction processes on the skid resistance durability of the pavement. Figure 19 shows the surface $3 \mathrm{D}$ structure of the specimens with different construction processes.

It can be seen from Figure 19 that the surface structure of the skid resistance fog seal-test specimen constructed using the one asphalt one sand process has the largest depth, which is characterized by the largest height difference but uneven distribution. This is because the skid resistance particles are spread on the fog seal asphalt and asphalt cannot completely cover the antislip particles. Therefore, the structure depth is relatively large, but spreading the skid resistance particles by hand results in poor uniformity because the skid resistance particles are spread between the two layers of fog seal asphalt, and the wrapping performance is better than the one asphalt one sand process. However, the skid resistance particles inevitably follow sliding when the surface layer of the fog seal asphalt is applied, resulting in a relatively concentrated phenomenon in the center of the skid resistance particles. In addition, the premixing process has the advantages of the above two processes. The surface height difference in the skid resistance fog seal layer specimens constructed by it is the smallest, and the overall uniformity of the specimens is excellent. This is because the premixing process first mixes and stirs the skid resistance particles and the fog seal asphalt to a specific proportion. The skid resistance particles are suspended in the fog seal asphalt in a specific gradation. After the skid resistance fog seal layer is sprayed, the skid resistance particles are evenly distributed and completely covered by the fog seal asphalt. Although the initial structure depth is reduced, the uniformity and skid resistance durability can be improved.

3.5.2. Skid Resistance Durability. Figures 20 and 21 show the BPN abrasion law of the skid resistance seal-test specimens formed by three construction processes and the mass loss rate after 100,000 abrasions.

It can be seen from Figures 20 and 21 that after the three skid resistance fog seals are formed, the initial BPN of the premixed process specimen is the smallest, and the initial $\mathrm{BPN}$ of the one-bitumen-one-sand process specimen is the largest. This is because the premixed process fully coats the skid resistance particles with the fog seal asphalt, causing the skid resistance particles to lose their angularity and reduce the surface roughness. In the early stage of abrasion, the BPN 

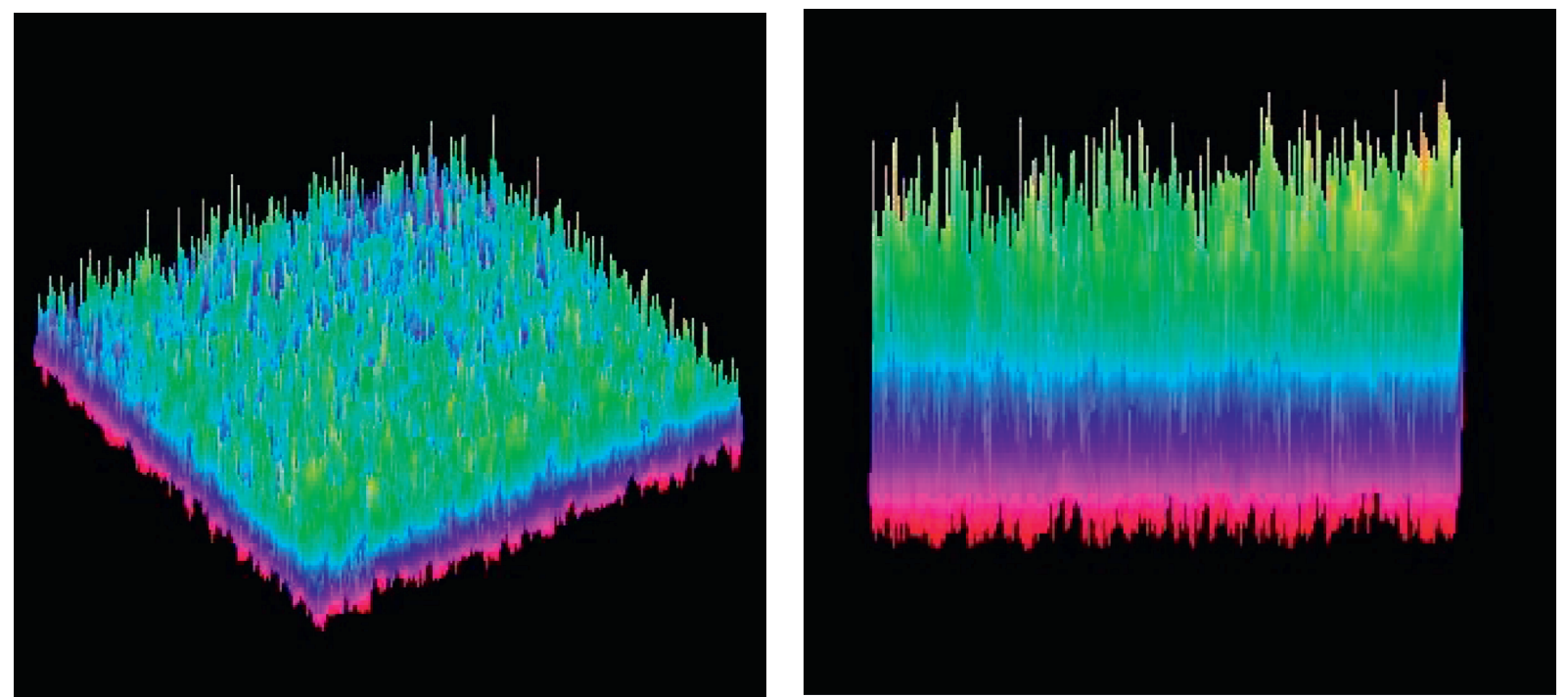

(a)
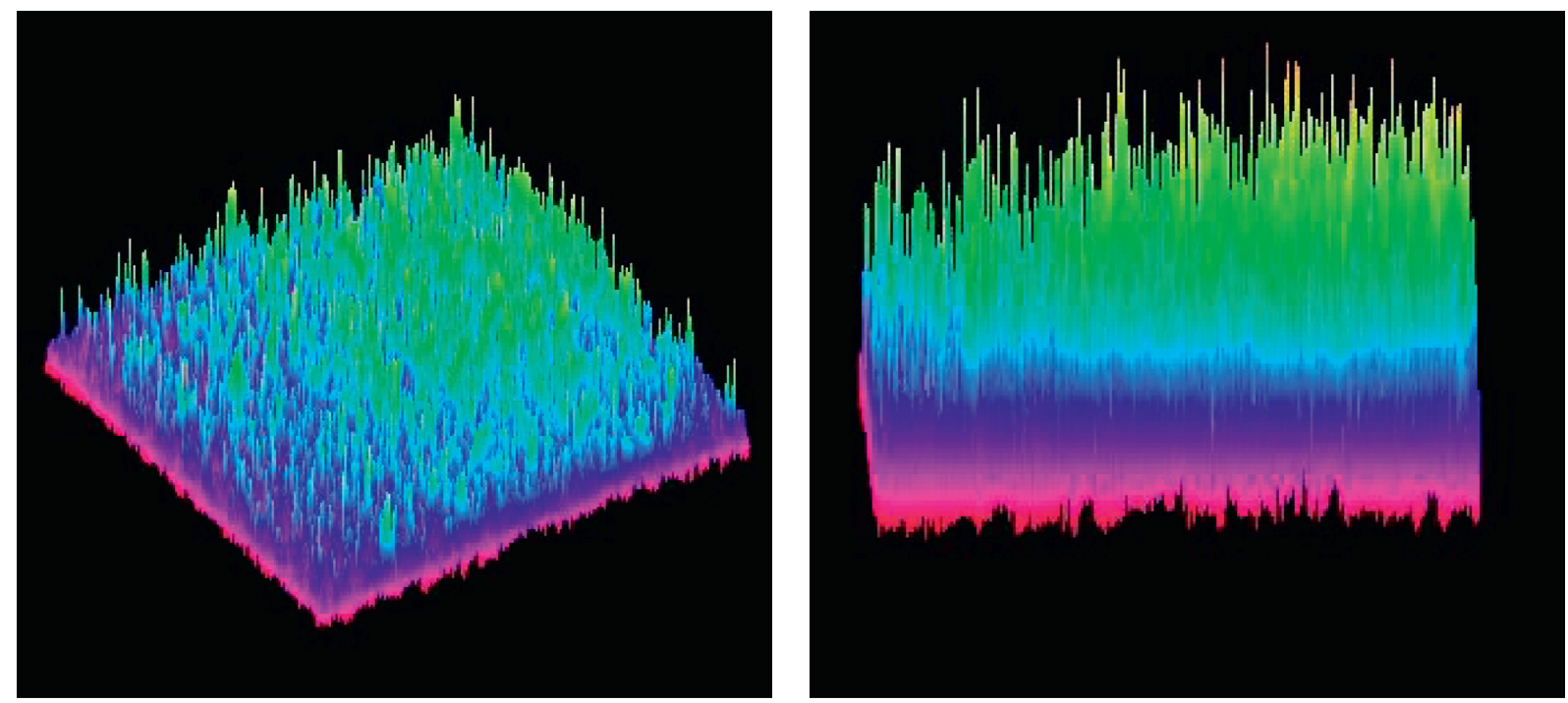

(b)
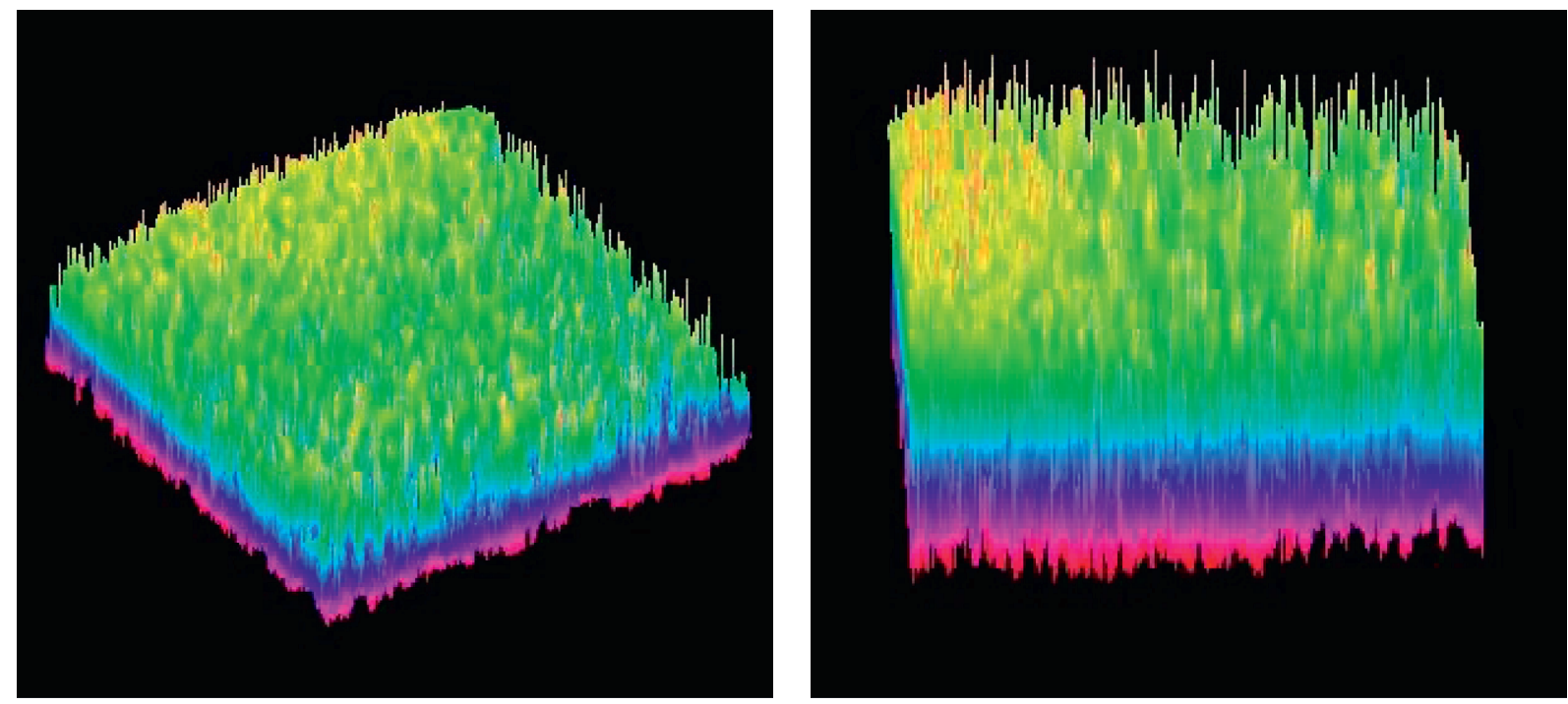

(c)

FIGURE 19: The 3D structure of the surface of the specimen with different construction process: (a) one asphalt one sand; (b) double asphalt one sand; (c) premix process. 


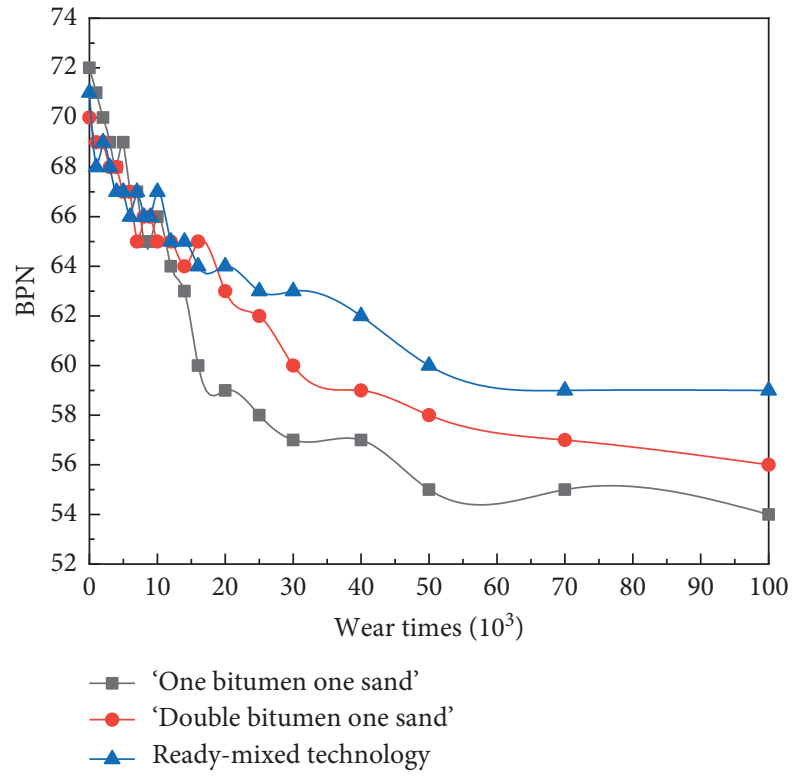

FIgURE 20: BPN wear law of different processes.

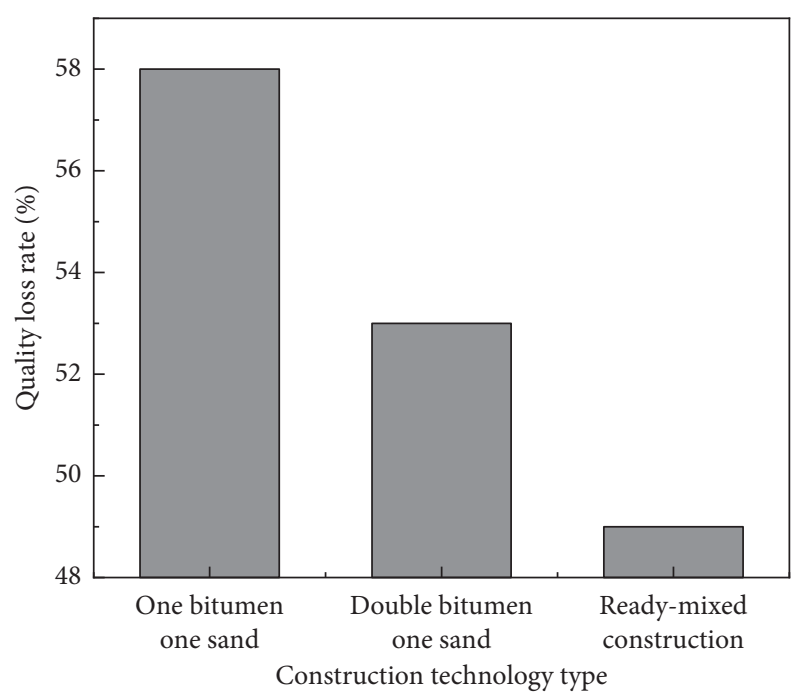

FIgURE 21: Quality loss rate of different processes.

of the one asphalt and one sand specimen decreased rapidly. When the abrasion was 30,000 times, the BPN decreased by $20.8 \%$. Simultaneously, the BPN of the double asphalt and one sand specimen and the premixed process specimen decreased by $14.3 \%$ and $7.4 \%$, and the decline of BPN was relatively flat. What is more, after 100,000 times of wear, the $\mathrm{BPN}$ of the three types of specimens was reduced by $25.0 \%$, $20.0 \%$, and $13.2 \%$. The BPN of the specimens formed by the premixed process had the smallest decrease and the skid resistance durability was better. The premixed process can fully coat the fog sealing asphalt and the skid resistance particles, increase the adhesion area of the antislip particles and mist sealant, and further enhance the bonding force, so the skid resistance particles are not easy to be worn away. The premixed process shows better skid resistance performance and wear resistance. Moreover, after 100,000 times of wear, the mass loss rates were $58.0 \%, 53.1 \%$, and $49.3 \%$. Compared with the one asphalt and one sand and double asphalt and one sand specimens, the premixed specimens had a reduced quality loss rate of $15.0 \%$ and $7.2 \%$, respectively, and it has better wear resistance.

In summary, the skid resistance fog seal layer formed by the premixed process has better skid resistance performance and wear resistance. This also verifies the $3 \mathrm{D}$ structure map of the surface of the skid resistance fog seal-test specimens formed by different construction processes. Therefore, it is recommended to use the premixed process for constructing the skid resistance fog seal.

\section{Verification of Skid Resistance Fog Seal Performance}

\subsection{Microscopic Analysis of Cured Epoxy-Emulsified Asphalt}

4.1.1. Microscopic Morphology of Cured Product. The samples of the cured product with the best formulation of the molded epoxy-emulsified asphalt were, respectively, subjected to tensile fracture surface, petroleum ether etching, and gold spray treatment on the surface. Quanta200 environmental scanning electron microscope was used to observe the cross section and surface appearance structure of the sample $(20 \mathrm{kV})$. Figure 22 shows the microstructure.

Figure 22 shows that the fracture surface of the cured product is rough and uneven, and the fracture toughness is good. After the surface of the sample is treated with petroleum ether, the asphalt is etched and the epoxy network skeleton is visible. The epoxy system (epoxy resin and curing agent) in the cured product can form a continuous $3 \mathrm{D}$ network structure, which has good mechanical properties and can effectively improve the strength and wear resistance of the asphalt material.

4.1.2. Thermal Stability. The Pyris-II comprehensive thermal analyzer (TG-DTA) was used to analyze the thermal stability of the epoxy-emulsified asphalt-cured product and the common asphalt samples of the fog seal. Among them, the flow rate of the nitrogen atmosphere was set to $50 \mathrm{~mL} /$ $\mathrm{min}$, and the temperature rise rate is $5^{\circ} \mathrm{C} / \mathrm{min}$. Figure 23 shows the thermogravimetric (TG) analysis curve of the cured products of commonly used asphalt and thermosetting fog seal asphalt for fog seal layers.

Figure 23 shows that the TG curves of the two materials are in the same trend, and each has a thermal weight loss platform. For the commonly used asphalt for fog seals, the initial thermal weight loss temperature is about $380^{\circ} \mathrm{C}$, and the temperature is completely decomposed or oxidized when the temperature rises to $490^{\circ} \mathrm{C}$. The temperature decomposition interval is $110^{\circ} \mathrm{C}$, and the initial thermal weight loss temperature of epoxy-emulsified asphalt-cured product is about $300^{\circ} \mathrm{C}$ and is completely decomposed or oxidized at $460^{\circ} \mathrm{C}$. Therefore, the initial thermal weight loss temperature is lower than that of fog seals, but the temperature decomposition interval is $160^{\circ} \mathrm{C}$, which is higher than the temperature decomposition interval of commonly used 


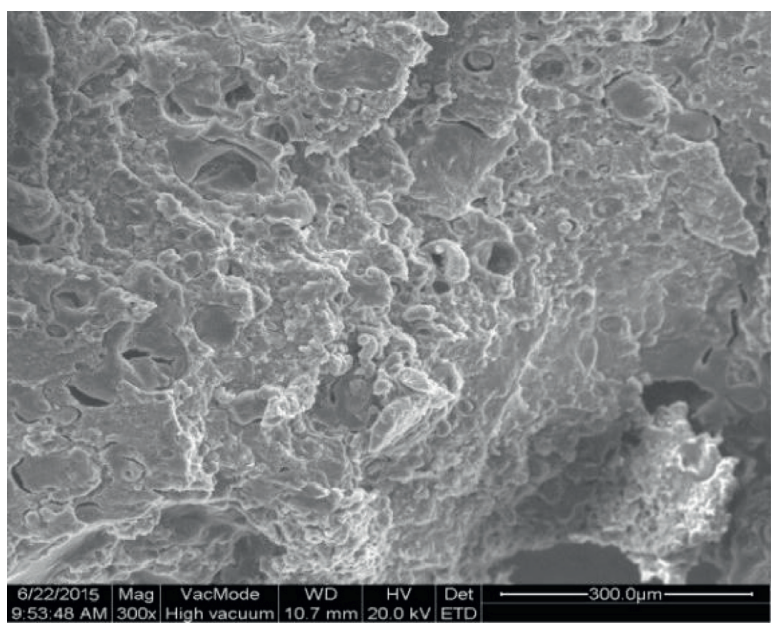

(a)

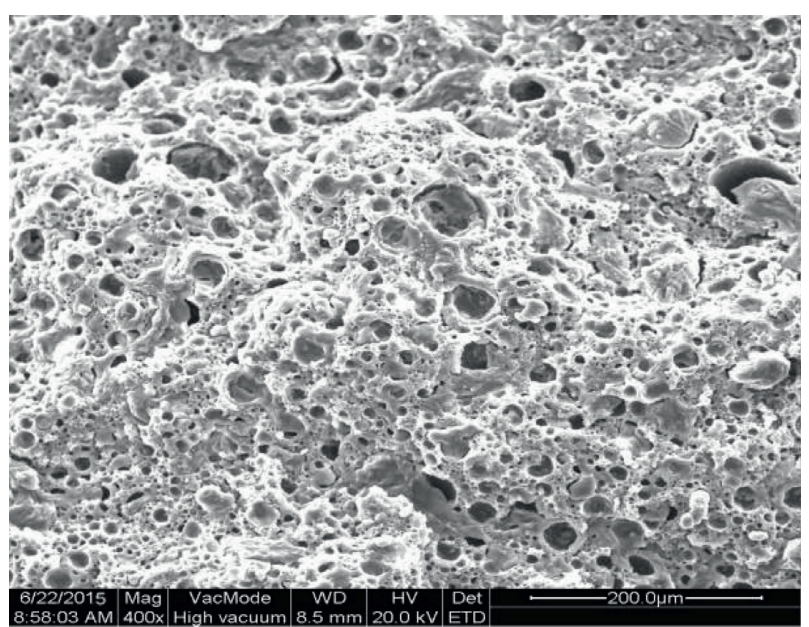

(b)

FIGURE 22: Micromorphology of cured epoxy-emulsified asphalt: (a) Internal section; (b) Surface.

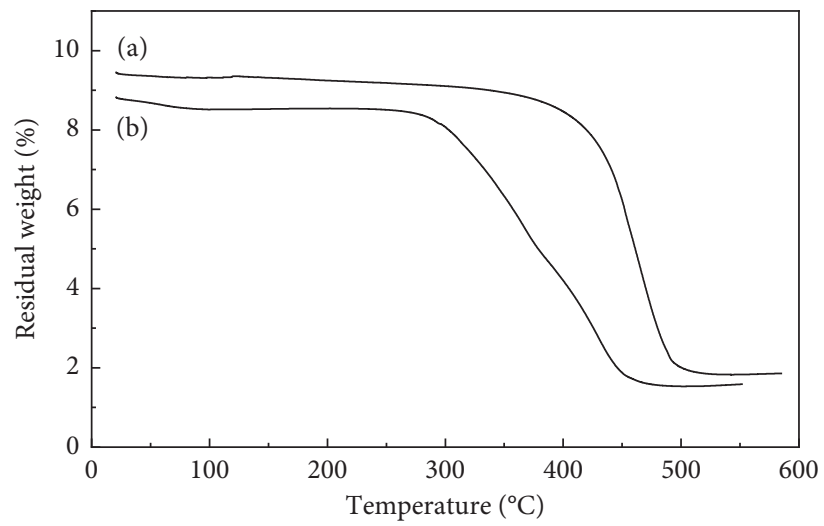

FIGURE 23: Thermogravimetric analysis curve of cured product: (a) commonly used asphalt-cured product for fog seal layer; (b) epoxy emulsified asphalt-cured product.

asphalt for fog seals. Although the initial thermal weight loss temperature of the cured product is lower than the commonly used mist seal layer, it is higher than the environmental aging temperature. The incorporation of the epoxy resin system extends the temperature decomposition range of the material and slows the oxidation or decomposition rate of asphalt. Therefore, the cured epoxy-emulsified asphalt has better thermal stability and can improve the hightemperature resistance of the road surface when it is used as a fog sealing asphalt.

4.2. Verification of Skid Resistance Durability of Skid Resistance Fog Seal. Under the optimum dosage of each component being studied, Figures 24 and 25 study the BPN abrasion law and mass loss rate after 100,000 abrasions of different asphalt type skid resistance fog seal samples, respectively.

Figures 24 and 25 show that during the abrasion process, the BPN curve of the fog seal-test specimens formed by epoxy-emulsified asphalt is on the upper side, which has better skid resistance performance and durability. The mass

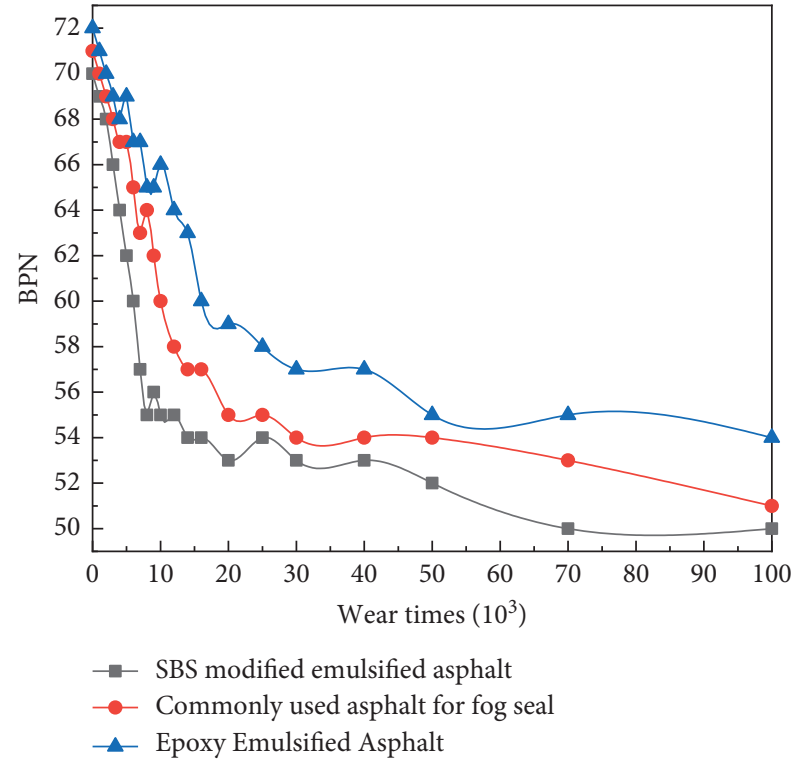

Figure 24: BPN abrasion law. 


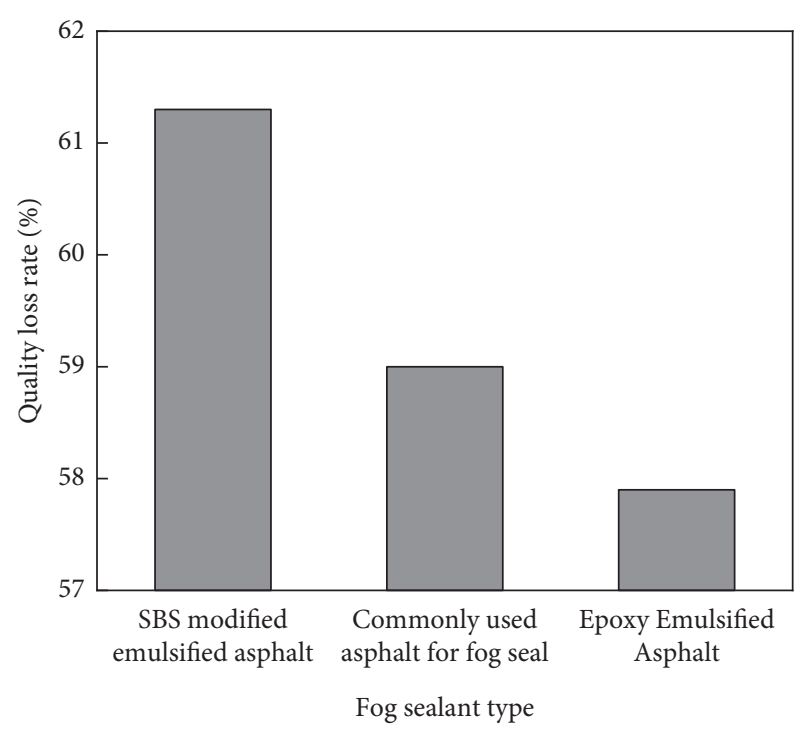

FIgUre 25: The mass loss rate.

loss rates of the three specimens after abrasion were $61.3 \%$, $59.1 \%$, and $58.0 \%$, respectively. Compared with SBS-modified emulsified asphalt and the commonly used asphalt for fog seals, the mass loss rates of epoxy-emulsified asphalt specimens were reduced by $5.4 \%$ and $1.9 \%$, with better wear resistance. In summary, when epoxy-emulsified asphalt is used as a mist seal binder, the skid resistance fog seal layer has better skid resistance performance and abrasion resistance.

\section{Conclusion}

The following conclusion were obtained from the results of the study:

(1) Combining the best bonding performance (bonding shear strength: $0.66 \mathrm{MPa}$ ), the best high-temperature water damage resistance $\left(\mathrm{MS}_{0}\right.$ : 97.7$)$, and an excellent aging resistance performance (mass loss rate: $3.57 \%$, aging classification: Level I), the number of the best formula for epoxy emulsified asphalt is $\mathrm{A}_{80}\left(\mathrm{E}_{2}\right)$.

(2) The influence of the ratio of the amount of skid resistance particles to the amount of fog seal asphalt for the skid resistance durability of the skid resistance fog seal layer showed that when the ratio is $1: 1$, the skid resistance fog seals show better performance (after abrasion of 100,000 times, BPN value: 54 and mass loss rate: $58.9 \%$ ).

(3) The influence of the total amount of skid resistance fog sealing asphalt on the skid resistance durability of the skid resistance fog seal layer showed that, when the total amount approaches $1.2 \mathrm{~kg} / \mathrm{m}^{2}$, the skid resistance fog seal specimens show the best performance (after abrasion of 100,000 times, BPN value: 54 and mass loss rate: $58.9 \%$ ).

(4) The influence of the construction process on the performance of the skid resistance fog seal showed that, when choosing premixed process for construction, the skid resistance fog seal specimens show the best 3D surface texture performance (after abrasion of 100,000 times, BPN value: 57 and mass loss rate: $49.3 \%$ ).

(5) The microscopic morphology and high-temperature resistance of the cured product of the fog sealing asphalt have been verified, and the skid resistance durability of the epoxy emulsified asphalt fog seal is verified by comparing the commonly used asphalt of the fog seal layer and the SBS-modified emulsified asphalt.

\section{Data Availability}

The data used have been provided in the article.

\section{Conflicts of Interest}

The authors declare that they have no conflicts of interest.

\section{Acknowledgments}

The research was funded by the Scientific Project from Shaanxi Provincial Communication (No. 16-17k), the Scientific Research of Central Colleges of China for Chang'an University (Grant no. 300102218212), and the Scientific Project from Henan Provincial Communication (No. 2020J2-2 95).

\section{References}

[1] F. Seal Guidelines, "California department of transportation (CADOT)," 2003.

[2] N. Prapaitrakul, Freeman, T. John, and C. J. Glover, "Assessing the ability of fog seals to seal pavements, to rejuvenate in situ binder, and to retard binder oxidation asphalt pavements," Environmental Sciences, 2007.

[3] W. Lei, G. Fan, and L. Yu, "Comparison between the effects of phosphorous slag and fly ash on the C-S-H structure, longterm hydration heat and volume deformation of cementbased materials," Construction and Building Materials, vol. 250, Article ID 118807, 2020.

[4] N. Prapaitrakul, T. Freeman, and C. Glover, "Fog seal treatment effectiveness analysis of pavement binders using thet-test statistical approach," Petroleum Science and Technology, vol. 28, no. 18, pp. 1895-1905, 2010.

[5] P. Cui, S. Wu, H. Xu, and Y. Lv, "Silicone resin polymer used in preventive maintenance of asphalt mixture based on fog seal," Polymers, vol. 11, no. 11, p. 1814, 2019.

[6] H. I. Jeong and Y. R. Kim, "Performance evaluation of fog seals on chip seals and verification of fog seal field tests," Canadian Journal of Civil Engineering, vol. 42, no. 11, Article ID 150825143826008, 2015.

[7] B. Xu, M. Li, S. Liu, J. Fang, R. Ding, and D. Cao, "Performance analysis of different type preventive maintenance materials for porous asphalt based on high viscosity modified asphalt," Construction and Building Materials, vol. 191, pp. 320-329, 2018.

[8] J. H. Im and Y. R. Kim, "Methods for fog seal field test with polymer-modified emulsions development and performance 
evaluation," Transportation Research Record, no. 2361, pp. 88-97, 2013.

[9] C. Hu, J. Zhao, Z. Leng, M. N. Partl, and R. Li, "Laboratory evaluation of waterborne epoxy bitumen emulsion for pavement preventative maintenance application," Construction and Building Materials, vol. 197, pp. 220-227, 2019.

[10] P. Feng, H. Wang, X. Zhang, M. R. M. Hasan, Z. You, and J. Gao, "Study on workability and skid resistance of bio-oilmodified fog seal with sand," Journal of Testing and Evaluation, vol. 48, no. 3, pp. 2072-2092, 2020.

[11] S. Fei, X. Peng, H. Jing, and Y. Lin, "Analysis of the influence of waterborne epoxy resin on different sand-and-mist sealing materials," Building Materials World, vol. 37, no. 4, pp. 5-9, 2016.

[12] S. Han, T. F. Yao, X. Han, H. W. Zhang, and X. F. Yang, "Performance evaluation of waterborne epoxy resin modified hydrophobic emulsified asphalt micro-surfacing mixture," Construction and Building Materials, p. 249, 2020.

[13] Z. Jiu-peng, L. Pei-feng, X. Li, and X.-J. M. Laboratory, "Study on the permeability and skid resistance of asphalt pavement fog seal layer. CICTP 2015 efficient, safe and green multimodal transportation 15th COTA international conference of transportation," Professionals Proceedings, pp. 949-956, 2015.

[14] C. K. Estakhri and H. Agarwal, Effectiveness of Fog Seals and Rejuvenators for Bituminous Pavement Surf, Texas Transportation Institute, TX USA, 1991.

[15] P. Richard, P. Guenter, and R. Markus, Transparent Form Part with Scratch-Proof and Anti-mist Properties - Comprises PlateShaped Substrate and Anti-mist Layer with One Lower Edge Left Free: DE 1993.Aces, Final, Report[R], 1991.

[16] N. A. Qureshi, N. H. Tran, and D. Watson, "Effects of rejuvenator seal and fog seal on performance of open-graded friction course pavement," Maejo International Journal of Science \& Technology, vol. 7, no. 2, pp. 189-202, 2013.

[17] X. Chen, S. Ou, D. Wang, and C. Xiang, "Indoor accelerated loading test evaluation of the influence of fog seal on pavement anti-skid performance," Highway, no. 5, pp. 206-208, 2011, [in Chinese].

[18] C. Li, Z. Li, and X. Yue, "Application of key technology of solvent-based anti-skid fog sealing coat," East China Highway, no. 2, pp. 54-58, 2012, [in Chinese].

[19] M. Y. Yuan and M. M. Center, Application of Anti-skid Fog Sealing Coat in Asphalt Pavement Maintenance, 2018.

[20] N. Prapaitrakul, T. Freeman, and C. J. Glover, Analyze Existing Fog Seal Asphalts and Additives: Literature Review, Texas Transportation Institute, 2005.

[21] R. M. Islam, S. Arafat, and N. M. Wasiuddin, "Quantification of reduction in hydraulic conductivity and skid resistance caused by fog seal in low-volume pavements," Transportation Research Record, no. 2657, pp. 99-108, 2017.

[22] W. Lei, G. Fan, H. Yang, and Y. Wang, "Comparison of fly ash, PVA fiber, $\mathrm{MgO}$ and shrinkage-reducing admixture on the frost resistance of face slab concrete via pore structural and fractal analysis," Fractals, vol. 29, no. 2, Article ID 2140002, 2021.

[23] G. N. King and H. King, Spray-applied Surface Seal: Fog and Rejuvenator Seals, Transportation Research Board Meeting, 2008.

[24] N. prapaitrakul, T. Freeman, J. Charles, and Glover, Analyze Existing Fog Seal Asphalts and Additives, p. 12, 2005.

[25] S. C. Misra, J. A. Manson, and J. W. Vanderhoff, Modern Paint and Coatings, vol. 12, pp. 27-31, 1978.

[26] Gb/T 38990-2020, Waterborne Epoxylite Emulsified Binder Mixture for Road Engineering, Ministry of Housing and
Urban-Rural Development of the People's Republic of China, Beijing, China, 2020.

[27] Jtg E20-2011, Standard Test Methods of Bitumen and Bituminous Mixtures for Highway Engineering, People's Communications Press, Beijing, China, 2011.

[28] Jtg F40-2004, Technical Specifications for Construction of Highway Asphalt Pavements, People's Communications Press, Beijing, China, 2004.

[29] Z. Min, Z. Zhang, and W. Huang, "Fracturing performance of epoxy resin asphalt mixture with different asphalt body ratio," Journal of China Highway and Transport, vol. 24, no. 3, pp. 22-28, 2011, [in Chinese].

[30] W. Lei, R. Luo, W. Zhang, and M. Jin, "Effects of fineness and content of phosphorus slag on cement hydration, permeability, pore structure and fractal dimension of concrete," Fractals, vol. 29, no. 2, Article ID 2140004, 2021.

[31] X. Cai, D.-Y Wang, J.-G Zhang, and S.-X Zhang, "Indoor accelerated loading test on micro-surfacing coating," Journal of Zhejiang University Engineering Science, vol. 46, no. 5, pp. 791-797, 2012.

[32] J. Gao, H. Wang, Y. Bu, Z. You, X. Zhang, and M. Irfan, "Influence of coarse-aggregate angularity on asphalt mixture macroperformance: skid resistance, high-temperature, and compaction performance," Journal of Materials in Civil Engineering, vol. 32, no. 5, 2020.

[33] X. Cai, W. Huang, J. Liang, and K. Wu, "Study of pavement performance of thin-coat waterborne epoxy emulsified asphalt mixture," Frontiers in Materials, vol. 7, 2020.

[34] L. Chu, W. Guo, and T. F. Fwa, "Theoretical and practical engineering significance of British pendulum test," International Journal of Pavement Engineering, 2020.

[35] Q. Zhang, Y.-h. Xu, and Z.-g. Wen, "Influence of water-borne epoxy resin content on performance of waterborne epoxy resin compound SBR modified emulsified asphalt for tack coat," Construction and Building Materials, vol. 153, pp. 774-782, 2017.

[36] W. Lei, J. Min, and Z. Shi, "Investigation of microstructure of $\mathrm{C}-\mathrm{S}-\mathrm{H}$ and micro-mechanics of cement pastes under $\mathrm{NH}_{4} \mathrm{NO}_{3}$ dissolution by ${ }^{29}$ Si MAS NMR and microhardness," Measurement, vol. 185, Article ID 110019, 2021. 